\title{
Reference
}

NBS

Publi.

cations

NAT'L INST. OF STAND \& TECH

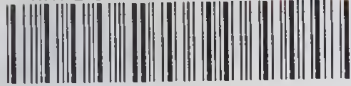

Alll 155974262

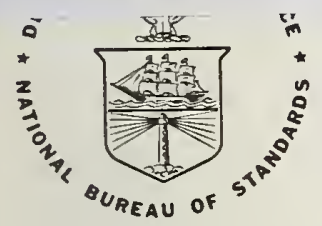

NBS TECHNICAL NOTE 1164

U.S. DEPARTMENT OF COMMERCE/National Bureau of Standards

\section{Measurement Assurance for Dimensional Measurements on Integrated-Circuit Photomasks}

$-Q C$

100

.45753

NO. 1164

1982 
The National Bureau of Standards' was established by an act of Congress on March 3, 1901. The Bureau's overall goal is to strengthen and advance the Nation's science and technology and facilitate their effective application for public benefit. To this end, the Bureau conducts research and provides: (1) a basis for the Nation's physical measurement system, (2) scientific and technological services for industry and government, (3) a technical basis for equity in trade, and (4) technical services to promote public safety. The Bureau's technical work is performed by the National Measurement Laboratory, the National Engineering Laboratory, and the Institute for Computer Sciences and Technology.

THE NATIONAL MEASUREMENT LABORATORY provides the national system of physical and chemical and materials measurement; coordinates the system with measurement systems of other nations and furnishes essential services leading to accurate and uniform physical and chemical measurement throughout the Nation's scientific community, industry, and commerce; conducts materials research leading to improved methods of measurement, standards, and data on the properties of materials needed by industry, commerce, educational institutions, and Government; provides advisory and research services to other Government agencies; develops, produces, and distributes Standard Reference Materials; and provides calibration services. The Laboratory consists of the following centers:

$$
\begin{aligned}
& \text { Absolute Physical Quantities }{ }^{2} \text { - Radiation Research - Chemical Physics - } \\
& \text { Analytical Chemistry - Materials Science }
\end{aligned}
$$

THE NATIONAL ENGINEERING LABORATORY provides technology and technical services to the public and private sectors to address national needs and to solve national problems; conducts research in engineering and applied science in support of these efforts; builds and maintains competence in the necessary disciplines required to carry out this research and technical service; develops engineering data and measurement capabilities; provides engineering measurement traceability services; develops test methods and proposes engineering standards and code changes; develops and proposes new engineering practices; and develops and improves mechanisms to transfer results of its research to the ultimate user. The Laboratory consists of the following centers:

Applied Mathematics - Electronics and Electrical Engineering ${ }^{2}$ - Manufacturing Engineering - Building Technology - Fire Research - Chemical Engineering ${ }^{2}$

THE INSTITUTE FOR COMPUTER SCIENCES AND TECHNOLOGY conducts research and provides scientific and technical services to aid Federal agencies in the selection, acquisition, application, and use of computer technology to improve effectiveness and economy in Government operations in accordance with Public Law 89-306 (40 U.S.C. 759), relevant Executive Orders, and other directives; carries out this mission by managing the Federal Information Processing Standards Program, developing Federal ADP standards guidelines, and managing Federal participation in ADP voluntary standardization activities; provides scientific and technological advisory services and assistance to Federal agencies; and provides the technical foundation for computer-related policies of the Federal Government. The Institute consists of the following centers:

Programming Science and Technology-Computer Systems Engineering.

'Headquarters and Laboratories at Gaithersburg, MD, unless otherwise noted; mailing address Washington, DC 20234.

${ }^{2}$ Some divisions within the center are located at Boulder, CO 80303. 


\section{Measurement Assurance for Dimensional Measurements on Integrated-Circuit Photomasks}

\section{NhS}

Carroll Croarkin

Ruth N. Varner

Statistical Engineering Division

Center for Applied Mathematics

National Bureau of Standards

Washington, DC 20234

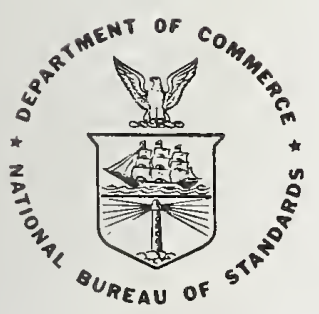

U.S. DEPARTMENT OF COMMERCE, Malcolm Baldrige, Secretary NATIONAL BUREAU OF STANDARDS, Ernest Ambler, Director 
National Bureau of Standards Technical Note 1164

Natl. Bur. Stand. (U.S.), Tech. Note 1164,50 pages (Aug. 1982)

CODEN: NBTNAE

U.S. GOVERNMENT PRINTING OFFICE

WASHINGTON: 1982

For Sale by the Superintendent of Documents, U.S. Government Printing Office, Washington, DC 20402.

(Add 25 percent for other than U.S. mailing.) 
This document has evolved from material presented as part of an on-going series of NBS training seminars on linewidth measurements for integrated-circuit photomasks and wafers sponsored by the Semiconductor Materials and Processes Division of the Center for Electronics and Electrical Engineering in cooperation with the Statistical Engineering Division of the Center for Applied Mathematics. The seminars are conducted under the NBS Semiconductor Technology Program which serves to focus NBS research on improved measurement technology for the semiconductor device community in specifying materials, equipment, and devices in national and international commerce, and in monitoring and controlling device fabrication and assembly. This research leads to carefully evaluated, well-documented test procedures and associated technology which, when applied by the industry, are expected to contribute to higher yields, lower cost, and higher reliability of semiconductor devices and to provide a basis for controlled improvements in fabrication processes and device performance.

The document is intended both as an instructional aid for future NBS training seminars on linewidth measurements and as a procedural guide for the calibration of an optical-microscope linewidth-measurement system using an NBS Optical Microscope Linewidth-Measurement Standard (SRM-474 or SRM-475) or any properly calibrated linewidth standard. It also serves as the basis for a standard method for calibration of an optical microscope for linewidth or linespacing measurement which is currently being prepared under the auspices of the American Society for Testing and Materials (ASTM) Subcommittee F-l on Electronics.

Special acknowledgment is gratefully made to the following NBS staff: $\mathrm{Dr}$. Diana Nyyssonen and Mr. John Jerke for their helpful suggestions and discussions; Dr. James Filliben for modifications to the software package DATAPLOT which produced the graphs and tables; Dr. Clifford Spiegelman for advice and consultation particularly in regard to the derivation of uncertainties; Dr. Lee Kieffer for suggestions for clarification on many points; and Mrs. Janet Couch for her expertise and patience in the preparation of the manuscript. Special acknowledgement is also made to the Office of Measurement Services of the National Bureau of Standards which supported this work. 
1. Introduction . . . . . . . . . . . . . . . . . . 1

2. What exactly is a calibration curve? . . . . . . . . . . . 4

3. Is the optical system in need of calibration and, if so, how is this accomplished?... . . . . . . . . . . . . . 5

4. What can go wrong with the calibration procedure?. . . . . . . 16

5. What is the precision of the optical system and how is it estimated? . . . . . . . . . . . . . . . . . . 18

6. How long will the derived calibration curve be adequate for correcting dimensional measurements? . . . . . . . . . . 20

7. Can the control data be used to update the calibration curve?. • . 26

8. What is the uncertainty of the values corrected by the calibration curve? . . . . . . . . . . . . . . . . . . 30 References . . . . . . . . . . . . . . . . 4 41 Appendix . . . . . . . . . . . . . . . . . . . 42

\section{LIST OF WORKSHEETS}

A. Calculations for a line-spacing calibration curve. . . . . . . . 10

B. Calculations for a linewidth calibration curve . . . . . . . . 14

C. Calculations for a pooled standard deviation . . . . . . . . . 19

D. Calculations for control of measurement process. . . . . . . . 23

E. Calculations for updating the calibration curve. . . . . . . . 28

F. Calculation of limits to error and uncertainty . . . . . . . . 33 
Page

1. Schematic diagram of calibration curve . . . . . . . . . . . 4

2. Differences between line-spacing measurements and NBS values plotted against NBS values............... . 9

3. Deviations of line-spacing measurements from a linear calibration curve plotted against NBS values . . . . . . . . . 9

4. Differences between linewidth measurements and corresponding NBS values plotted against NBS value . . . . . . . 13

5. Deviations of observed linewidths from linear calibration curve plotted against NBS values.................. . 13

6. Comparison of repetitions of linewidth measurements. . . . . . . 17

7. Control chart for opaque linewidths for data in Worksheet D . • . . 22

8. Differences of observed linewidths from NBS values plotted against NBS values. . . . . . . . . . . . . . . 24

9. Control values for the lower, mid and upper endpoints of data in Figure 7. ................... 24

\section{LIST OF TABLES}

1. Critical values of Student's $t$ distribution for a two-sided test . 34

2.1. Critical values of $t^{*}$ distribution for controlling the output of a calibration curve at m points at significance level $\alpha=0.0535$

2.2. Critical values of $t^{*}$ distribution for controlling the output of a calibration curve at m points at significance leve1 $\alpha=0.0136$

3.1. Percentage points of the $x^{2}$ distribution-lower $1 \%$ points. . . . 37

3.2. Percentage points of the $x^{2}$ distribution-lower $5 \%$ points. . . . 38

4.1. Percentage points of the F distribution-upper $1 \%$ points . . . 39

4.2. Percentage points of the F distribution-upper $5 \%$ points . . . 40 

Measurement Assurance for Dimensional

Measurements on Integrated-Circuit Photomasks

\author{
Carroll Croarkin \\ Ruth N. Varner \\ Statistical Engineering Division \\ Center for Applied Mathematics \\ National Bureau of Standards \\ Washington, DC 20234
}

Optical Microscope Linewidth-Measurement Standards, SRM-474 and SRM-475, have been developed by NBS for optical imaging systems capable of making line-spacing and linewidth measurements in the $0.5 \mu \mathrm{m}-12 \mu \mathrm{m}$ regime on IC photomasks. Each artifact affords a means of reducing systematic errors via a calibration curve and keeping the optical system in statistical control. Procedures are given for accomplishing these goals along with a discussion of the uncertainty of the calibrated values.

Key Words: IC photomask; linear calibration curve; line-spacing; linewidth; measurement assurance; photomask; SRM; statistical control of measurement process; tests for systematic error; uncertainty.

\title{
1. Introduction
}

Optical imaging systems which use an optical microscope fitted with some type of measurement attachment are commonly used for line-spacing and linewidth measurements in the $0.5 \mu \mathrm{m}-12 \mu \mathrm{m}$ regime on integrated circuit (IC) photomasks. In an effort to provide the microelectronics industry with calibration standards for determining and reducing systematic errors in line-spacing and linewidth measurements, the National Bureau of Standards undertook to develop a dimensional artifact and procedures for calibrating a variety of measurement systems. References [1], [2], and [3] describe this effort.

Past attempts to improve the accuracy of linewidth measurements have been hampered by the lack of a suitable linewidth artifact and misconceptions about the nature of line-spacing and linewidth measurements. Linewidth determination is a more difficult measurement than line-spacing determination. Line-spacing measures the displacement between two objects; it can be a left-edge to left-edge, right-edge to right-edge, or center to center measurement in which the errors in detecting the line edges cancel each other. Linewidth measures the width of a physical object; it is basically a left-edge to right-edge measurement in which the errors in detecting the edges are additive. Therefore, systematic errors in linewidth measurements are fundamentally related to edge detection [4] and to a lesser extent may also depend upon the inherent metric or line-spacing calibration of the system. Theory of the optical microscope in relation to linewidth measurements is discussed in references [5] and [6]. 
In the absence of a linewidth standard, the IC industry has sometimes relied on line-spacing calibration to resolve the linewidth measurement problem. This relationship was investigated in an NBS sponsored interlaboratory study involving ten IC companies [2]. Of the twenty systems analyzed in the study, only seven had substantial systematic line-spacing errors while seventeen of the systems had substantial systematic linewidth errors. A line-spacing calibration curve created for each of the seven systems with line-spacing offsets from NBS was used to correct linewidth data for those systems. In no case did the line-spacing correction eliminate the linewidth errors although it did reduce some substantially. In at least one case the offset was worse after correction. As far as systems in the study are representative of optical systems available in the industry at this time, it does not seem reasonable to expect a correction for metric to solve the linewidth measurement problem.

A solution to the linewidth measurement problem is made possible by the development of SRM-474 and SRM-475. The two artifacts are essentially the same except that the former contains four rows of lines, alternately opaque and clear, which are calibrated for linewidth; the latter contains only two rows of lines. Each row contains ten randomly arranged lines in the regime from $0.5 \mu \mathrm{m}$ to $12 \mu \mathrm{m}$. In addition, both SRMs contain a row of ten randomly arranged spacings in the regime $0.5 \mu \mathrm{m}$ to $12 \mu \mathrm{m}$.

The procedures in this document serve as a guide for establishing a measurement assurance program for linewidth or line-spacing measurements. The measurement assurance concept as set forth in reference [7] requires that a measurement system be tied to a defined unit of measurement or to a single measurement system such as the NBS system. The line-scale of an optical system is tied to the defined unit of length (wavelength of radiation of krypton 86) [8] by a calibration curve derived from measurements made on the calibrated spacings on the SRM. The linewidth capability of an optical system is tied to the unit of length via an NBS photometric system in which the image profile of the calibrated lines on the SRM are made to agree with theoretical profiles within the reported uncertainty [9]. This is accomplished by adherence to NBS recommended procedures for adjusting the microscope [10] and by a calibrated curve derived from measurements made on the calibrated lines on the SRM.

The measurement assurance concept also requires that the measurement system be maintained in a state of control, thus assuring that the uncertainty ascribed to the output of the system is valid at all times. Methods suggested for maintaining control on the values reported by the calibrated system and for computing the associated total uncertainty are applicable to either a linewidth or line-spacing discipline.

Although the procedures outlined in this document specify the use of SRM-474 or SRM-475, they are valid for any properly calibrated dimensional artifact as long as it is understood that several substantial issues such as the proper form of the calibration curve and possible sources of error should be addressed before attempting to adapt this analysis to a particular situation. Attention should be given to the discussions in section 4 concerning between-day differences in the calibration curve, the linearity assumption, and operator differences, keeping in mind that any problems in these areas must be resolved for a valid application of the calibration curve. 
All analyses are illustrated using measurements made on an artifact similar to SRM-474 by a participant in the interlaboratory study. The raw data from the interlaboratory study are reported to two decimal places. Calculations were made via a computer, and the results are rounded to four decimal places in most of the tables. Consequently, values calculated from these rounded values may vary slightly from those reported in this document.

As a final note, the term system as used in this publication should not be thought of as only the microscope and measurement attachment per se but as the total configuration of operator, environment and apparatus that go into producing a measurement. It is recommended that a minimum of four sets of measurements be made of the lines or spacings on the SRM in order to establish a calibration curve for an optical system. The calibration curve will be valid for the system only insofar as the initial measurements that produce the calibration curve are representative of operating conditions and only as long as the system response remains in a state of control. 


\section{What exactly is a calibration curve?}

Calibration is a process of intercomparing an unknown with a standard and assigning a value to the unknown based on the accepted value of the standard. The intercomparison can also be accomplished by treating the standard as if it were an unknown in the user's measurement process, thus eliminating any offset that may exist between the user's measurement system and the measurement system used by the laboratory such as NBS, which measured the standard. When the intercomparisons are extended over a measurement regime of interest and a functional relationship is shown to exist between the user's measurements and the accepted values for the standard, the assignment of values to the user's system is based on this functional relationship.

For the present exercise, the NBS dimensional artifact covering the $0.5 \mu \mathrm{m}-12 \mu \mathrm{m}$ regime is the standard, and measurements made on the individual lines on the artifact with an optical imaging system form the basis for establishing a functional relationship between the two systems. A least-squares technique is employed to derive a best fitting straight line to the measured linewidths as a function of the NBS values. This empirical fit is called the calibration curve.

In Figure 1, each optical measurement is plotted against the corresponding NBS value, and the calibration curve fitted to all the measurements is shown by the solid line. The offset between the user's system and the NBS system is reduced by relating any future linewidth value back to the NBS value. Schematically, for a future linewidth value $y(T)$ as shown on the $y$-axis, a dotted line is drawn through $\mathrm{y}(\mathrm{T})$ parallel to the $\mathrm{x}$-axis. At the point where it intersects the calibration curve another dotted line is drawn parallel to the $y$-axis, and its point of intersection on the $x$-axis, $x(T)$, is the corresponding calibrated value relative to NBS.

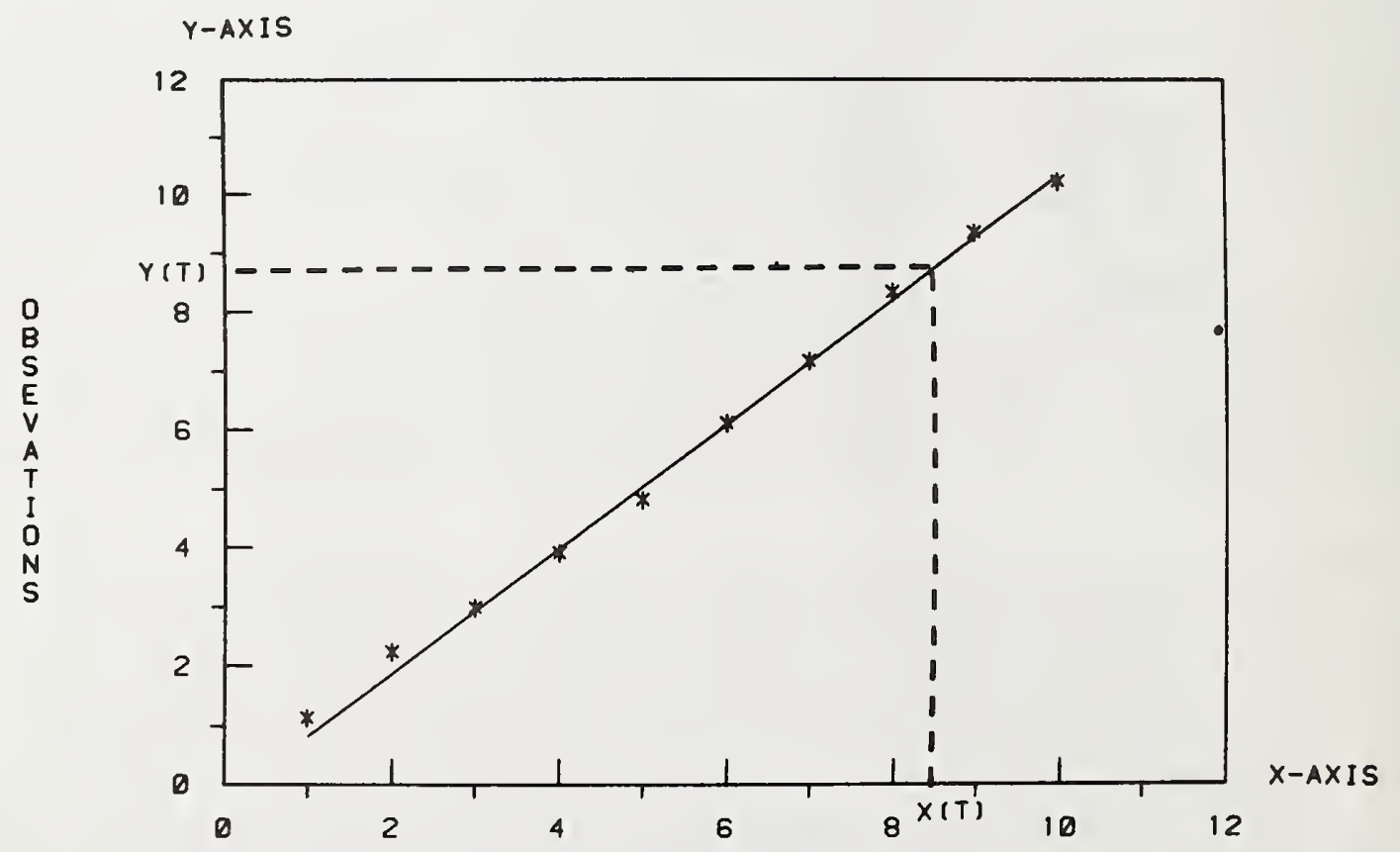

NBS VALUES

Figure 1. Schematic Diagram of Calibration Curve 
3. Is the optical system in need of calibration and, if so, how is this accomplished?

The question of whether or not a calibration is needed for an optical imaging system can be resolved by applying the procedures in this section to measurements made on the NBS artifact. If a calibration is indicated, the same measurements are used to construct a calibration curve which in turn is used to correct all future measurements on the optical systems.

The determination of systematic error is made independently for 11ne-spacing and linewidth measurements. A line-spacing calibration curve for reducing systematic line-spacing errors is derived from measurements on the ten line-spacings on the SRM. Linewidth calibration curves for reducing systematic linewidth errors for opaque and clear lines are derived from measurements on the ten opaque lines and the ten clear lines on the SRM. Separate calibration curves are needed for each polarity because it is expected that offsets for clear lines will be in the opposite direction from offsets for opaque lines.

A minimum of four repetitions of the measurements on the ten lines or spacings on the SRM are needed in order to establish a calibration curve. These repetitions should be spaced over roughly a two-week interval to ensure independence among the measurements, and it is reemphasized that the efficacy of the calibration curve as a device for reducing systematic errors is dependent upon the repetitions being truly representative of operating conditions in the laboratory. The user is further cautioned that different operators may produce measurements with systematic errors that are substantially different in sign or in magnitude, thereby necessitating separate calibration curves for each operator.

The procedures and analyses that are set forth in this publication are intended for either line-spacing or linewidth measurements. Because it is anticipated that the majority of users will be primarily concerned with linewidth determination, the text and examples are in terms of linewidth, but the total content including equations and tests are equally applicable to line-spacing measurements. Examples of the derivation of both a line-spacing calibration curve and a linewidth calibration curve are included at the end of this section.

To return to the calibration question, it is noted that an optical imaging system with negligible linewidth errors will exhibit the following characteristics. The observed linewidths will be a linear function of the nominal linewidth values assigned to the artifact by NBS. This linear function will have a slope $b=1$ and an intercept $a=0$, and the scatter about the fitted line will be sufficiently small for the system.

The thrust of the remainder of this section is to examine the relationship between the NBS values for the linewidths and the user's observations on the lines. This is accomplished by fitting the observed linewidths to a linear function of the NBS linewidth values and testing the resulting estimates of the slope and intercept for the characteristics cited above. If these tests show that linewidth errors are not negligible, thus indicating a need for correction to the optical system, the fitted curve becomes the calibration curve for the system. 
Before undertaking this analysis on the data, it is suggested that the differences between the observed linewidths and the corresponding NBS values be plotted against the NBS values. Any truly aberrant or oscillatory behavior of the system will show up on the plot, and such behavior obviously precludes using such data to calibrate the system.

A plot of the differences will also make it easier to identify any outliers that are present in the data set. For the purpose of this exercise an outlier is defined as any measurement that is obviously inconsistent with the other measurements in the data set whether it be an individual point or a group of points representing a single repetition. Any such discordant points should be deleted from the data set because even a single isolated outlier can seriously perturb the calibration curve. An outlier can be particularly disruptive if it happens to lie near one of the endpoints of the calibration interval.

Formal tests for outliers are not given in this publication, but they are discussed in detail in reference [11]. A careful study of the difference plot should be adequate for spotting outliers. When one is satisfied that the data set is free of any discordant points and that it consists of measurements that are representative of the diversity of conditions affecting the measurement system, then the following analysis is performed.

Given linewidth measurements $z_{i j}$ and corresponding NBS linewidth values $w_{i j}$ $(i=1, \ldots, k ; j=1, \ldots, 10)$ where $i$ denotes the repetition and $j$ denotes the linewidth, least-squares estimates are obtained for a linear function of the form

$$
z_{i j}=a+b w_{i j} \quad \begin{aligned}
& i=1, \ldots, k \\
& j=1, \ldots, 10
\end{aligned}
$$

The equations for estimating the parameters are as follows:

$$
\begin{gathered}
\hat{b}=\frac{\sum_{i j} \sum_{j}\left(w_{i j}-\bar{w}\right)\left(z_{i j}-\bar{z}\right)}{\sum_{i j} \sum_{j}\left(w_{i j}-\bar{w}\right)^{2}} \\
\hat{a}=\bar{z}-\hat{b} \bar{w} \\
\text { where } \quad \bar{w}=\frac{\sum_{j} \sum_{j} w_{i j}}{n} \text { and } \bar{z}=\frac{\sum \sum_{j} z_{i j}}{n}
\end{gathered}
$$

The deviations from the linear fit are

$$
\delta_{i j}=z_{i j}-\hat{a}-\hat{b} w_{i j}
$$

and the residual standard deviation of the linear fit is 


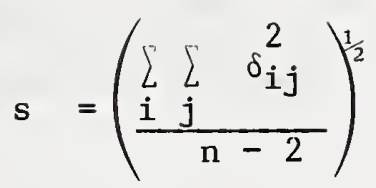

where $\mathrm{n}$ is the total number of observations, $\mathrm{n}=10 \mathrm{k}$.

Before proceeding with the tests for the slope and intercept, one should be satisfied that a linear function is indeed a good characterization of the system response as a function of the assigned values of the lines. A formal statistical test for deciding the appropriateness of a linear function is given in the appendix. A plot of the deviations from the linear fit provides considerable insight into this question.

The deviations are perhaps the best diagnostic tool for deciding whether or not the linear fit is a proper representation of the relationship between the NBS values and the user's system. The deviations, when plotted against the NBS values, should scatter randomly about a line drawn horizontal to the x-axis at zero with approximately an equal number of points falling above and below the line. Any apparent cyclic behavior or obvious clustering of the deviations is evidence that a linear fit is not appropriate. The NBS artifact is designed only for systems with linear responses and probably cannot be used if a higher order curve is indicated because of the limited number of lines on the artifact.

Test statistics, $t_{1}$ and $t_{2}$, for testing if the intercept $a=0$ and if the slope $b=1$, respectively, are as follows [12]:

$$
t_{1}=\frac{a}{s_{a}} \quad t_{2}=\frac{1-b}{s_{b}}
$$

where

$$
s_{a}=s\left(\frac{\sum_{i j} \sum_{i j}^{2}}{\left.n \sum_{i j} \sum_{i j}-w\right)^{2}}\right)^{\frac{1}{2}} \text { and } s_{b}=\frac{s}{\left(\sum_{i j}\left(w_{i j}-\bar{w}\right)^{2}\right)^{\frac{1}{2}}}
$$

A value of $\left|t_{1}\right|>t_{\alpha / 2}(n-2)$ indicates that the intercept a is significantly different from zero, and a value of $\left|t_{2}\right|>t_{\alpha / 2}(n-2)$ indicates that the slope $b$ is significantly different from one. 1 The parameters $a$ and $b$ are tested separately so that the nature of the systematic errors can be ascertained. If only the intercept is significantly different than assumed, the errors are constant, and a constant correction would be sufficient to reduce this source of error. If the slope is significantly different than assumed, the errors are related to width of the lines, and a calibration curve is used to correct for

1 For probability level $1-\alpha$ the critical value $t_{\alpha / 2}(\nu)$ can be found in a table of Student's $t$ distribution where $\nu$ is the number of degrees of freedom in the residual standard deviation of the fit. Critical values for $\alpha=0.05$ are tabulated in Table 1 for $\nu=30$ (2) 120. 
systematic errors. A significant value for either of these parameters implies that there are systematic linewidth errors and, as a practical matter, any future linewidth measurement $\mathrm{z}$ should be corrected by

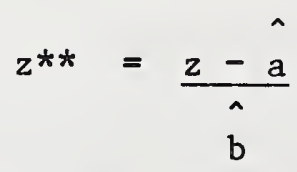

Calculations for a line-spacing calibration curve based on measurements that were made by a participant in the interlaboratory study on an artifact similar to SRM-474 are illustrated in Worksheet A. The calculations utilize four repetitions on the spacings, and the total number of observations is $n=40$.

Worksheet A lists the NBS assigned values of the line-spacings, the participant's observed values, and the differences between the observed and NBS assigned values. The differences are plotted against the NBS values in Figure 2 , and for the system to be properly adjusted for scale, these differences should be scattered randomly about the zero line drawn horizontal to the $\mathrm{x}$-axis. It is obvious from Figure 2 that the line-spacing scale of the system is offset from the NBS system and that the magnitude of this offset is related to the size of the spacing. This judgment is confirmed by the t-tests for the slope and intercept of the linear function that has been fit to the data. Both t-tests are significant.

The deviations from the linear fit are plotted in Figure 3. They are sufficiently random to conclude that a linear function is appropriate for the data. Because the t-tests for the intercept and slope are significant, all future line-spacing measurements should be corrected by the calibration curve as defined in equation 3.2 .

Calculations for a linewidth calibration curve based on measurements by the same participant in the interlaboratory study on the ten opaque lines on the same artifact are illustrated in Worksheet B. The calculation utilizes four repetitions on the opaque lines, and the total number of observations is $n=40$.

Worksheet B lists the NBS assigned values of the lines, the participant's observed values, and the differences between the participant's values and the NBS assigned values. The differences are plotted against the NBS values in Figure 4. It is obvious from Figure 4 that the linewidth calibration of the system is also offset from the NBS system and that the magnitude of this offset is related to the width of the lines. This is confirmed by the t-tests for the intercept and slope as shown in the worksheet.

The deviations from the linear fit are plotted in Figure 5. In this case, the deviations are randomly distributed about the zero line indicating that the linear fit is a good characterization of the data and that the calibration curve will adequately correct the system. Because the t-tests for the intercept and the slope of this linear function are significant, all future linewidth measurements should be corrected by equation 3.2 . 


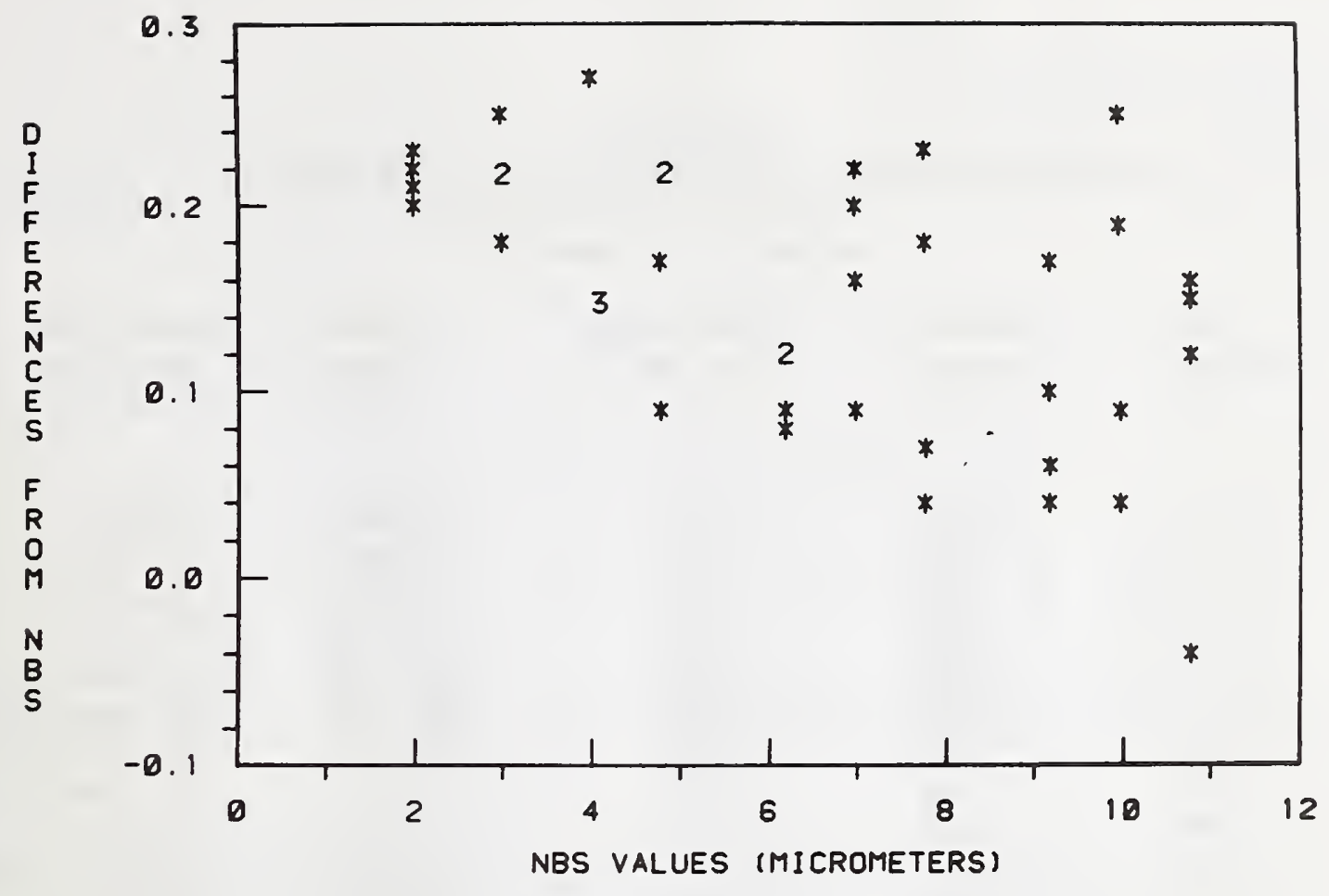

Figure 2: Differences between line-spacing measurements and NBS values plotted against NBS values.

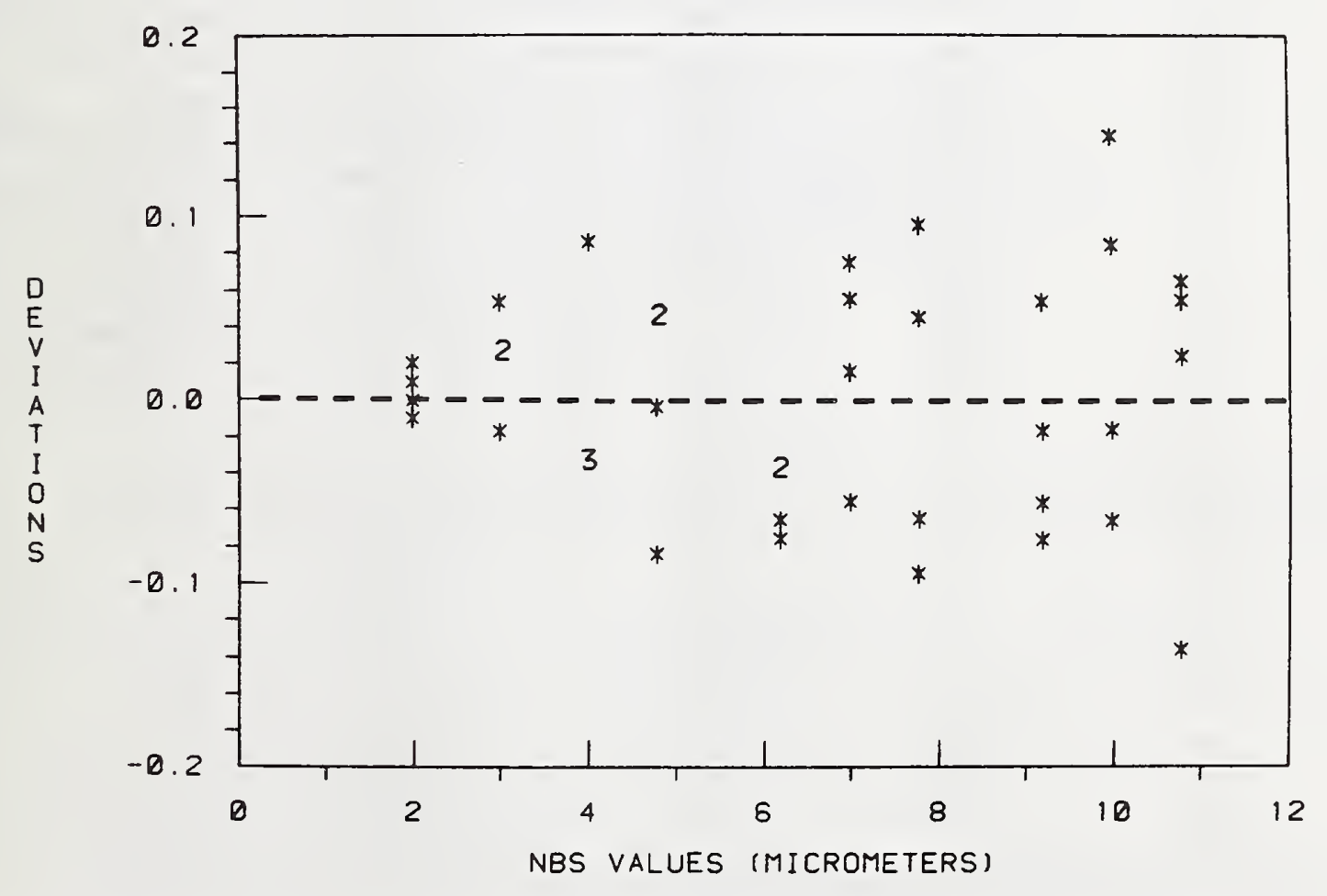

Figure 3: Deviations of line-spacing measurements from a linear calibration curve plotted against NBS values. 
Worksheet A

Calculations for Line-spacing Calibration Curve Line-Spacing Measurements

Values in Micrometers

$\begin{array}{ccccc}\text { NBS } & \text { Observed } & \text { Differences } & \text { Fitted } & \text { Deviations } \\ \text { Values } & \text { Values } & \text { From NBS } & \text { Value } & \text { From Fit } \\ \text { w } & z & d & z^{\prime} & \delta\end{array}$

\begin{tabular}{|c|c|c|c|c|}
\hline 6.19 & 6.31 & 0.12 & 6.3455 & -0.0355 \\
\hline 9.17 & 9.27 & 0.10 & 9.2869 & -0.0169 \\
\hline 1.99 & 2.21 & 0.22 & 2.2000 & 0.0100 \\
\hline 7.77 & 8.00 & 0.23 & 7.9050 & 0.0950 \\
\hline 4.00 & 4.27 & 0.27 & 4.1839 & 0.0861 \\
\hline 10.77 & 10.93 & 0.16 & 10.8662 & 0.0638 \\
\hline 4.78 & 4.95 & 0.17 & 4.9538 & -0.0038 \\
\hline 2.99 & 3.24 & 0.25 & 3.1870 & 0.0530 \\
\hline 6.98 & 7.14 & 0.16 & 7.1253 & 0.0147 \\
\hline 9.98 & 10.23 & 0.25 & 10.0864 & 0.1436 \\
\hline 6.19 & 6.27 & 0.08 & 6.3455 & -0.0755 \\
\hline 9.17 & 9.21 & 0.04 & 9.2869 & -0.0769 \\
\hline 1.99 & 2.19 & 0.20 & 2.2000 & -0.0100 \\
\hline 7.77 & 7.81 & 0.04 & 7.9050 & -0.0950 \\
\hline 4.00 & 4.15 & 0.15 & 4.1839 & -0.0339 \\
\hline 10.77 & 10.73 & -0.04 & 10.8662 & -0.1362 \\
\hline 4.78 & 4.87 & 0.09 & 4.9538 & -0.0838 \\
\hline 2.99 & 3.17 & 0.18 & 3.1870 & -0.0170 \\
\hline 6.98 & 7.07 & 0.09 & 7.1253 & -0.0553 \\
\hline 9.98 & 10.02 & 0.04 & 10.0864 & -0.0664 \\
\hline 6.19 & 6.31 & 0.12 & 6.3455 & -0.0355 \\
\hline 9.17 & 9.34 & 0.17 & 9.2869 & 0.0531 \\
\hline 1.99 & 2.22 & 0.23 & 2.2000 & 0.0200 \\
\hline 7.77 & 7.95 & 0.18 & 7.9050 & 0.0450 \\
\hline 4.00 & 4.15 & 0.15 & 4.1839 & -0.0339 \\
\hline 10.77 & 10.92 & 0.15 & 10.8662 & 0.0538 \\
\hline 4.78 & 5.00 & 0.22 & 4.9538 & 0.0462 \\
\hline 2.99 & 3.21 & 0.22 & 3.1870 & 0.0230 \\
\hline 6.98 & 7.18 & 0.20 & 7.1253 & 0.0547 \\
\hline 9.98 & 10.07 & 0.09 & 10.0864 & -0.0164 \\
\hline 6.19 & 6.28 & 0.09 & 6.3455 & -0.0655 \\
\hline 9.17 & 9.23 & 0.06 & 9.2869 & -0.0569 \\
\hline 1.99 & 2.20 & 0.21 & 2.2000 & 0.0000 \\
\hline 7.77 & 7.84 & 0.07 & 7.9050 & -0.0650 \\
\hline 4.00 & 4.15 & 0.15 & 4.1839 & -0.0339 \\
\hline 10.77 & 10.89 & 0.12 & 10.8662 & 0.0238 \\
\hline 4.78 & 5.00 & 0.22 & 4.9538 & 0.0462 \\
\hline 2.99 & 3.21 & 0.22 & 3.1870 & 0.0230 \\
\hline 6.98 & 7.20 & 0.22 & 7.1253 & 0.0747 \\
\hline 9.98 & 10.17 & 0.19 & 10.0864 & 0.0836 \\
\hline
\end{tabular}


Calculations for finding a spacing calibration curve such that $z=a+b w$ for $n$ measurements:

Estimate of slope

Estimate of intercept

$$
\mathrm{n}=10 \mathrm{k}=40
$$

Differences from NBS

$\mathrm{d}=\mathrm{z}-\mathrm{w}$

$\bar{w}=\sum \sum w / n=6.462$

$\bar{z}=\sum \sum \mathrm{z} / \mathrm{n}=6.614$

$\hat{b}=\Sigma \Sigma(w-\bar{w})(z-\bar{z}) / \Sigma \Sigma(w-\bar{w})^{2}=0.9870$

$\hat{a}=\bar{z}-\hat{b} \bar{w}=0.2358$

Deviations from linear fit

$\delta=z-z^{\prime}$ where $z^{\prime}=\hat{a}+\hat{b} w$

Standard deviation from linear fit $s=\sqrt{\Sigma \delta^{2} /(n-2)}=0.06203$

with degrees of freedom $n-2=38$

Student's t-test for intercept:

Standard deviation of $a \quad s_{a}=s \sqrt{\frac{\sum \sum w^{2}}{n \sum \sum(w-\bar{w})^{2}}}=0.02430$

T statistic for intercept $t_{I}=\hat{a} / \mathrm{s}=9.7$

Critical value $t .025(38)=2.0$

$t_{l}>t_{.025}$ implies a is significantly different

Student's t-test for slope:

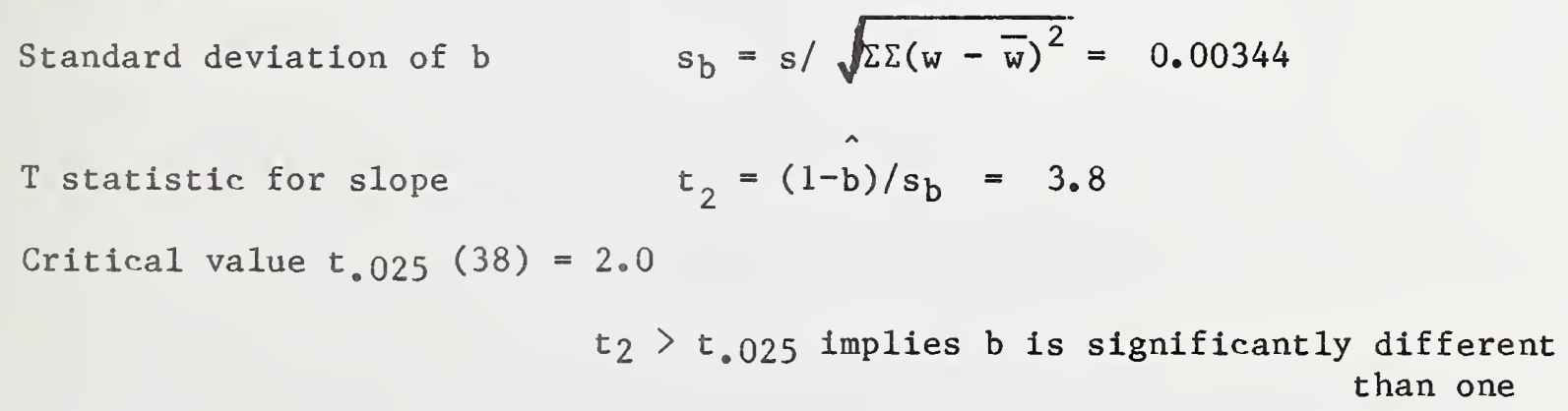





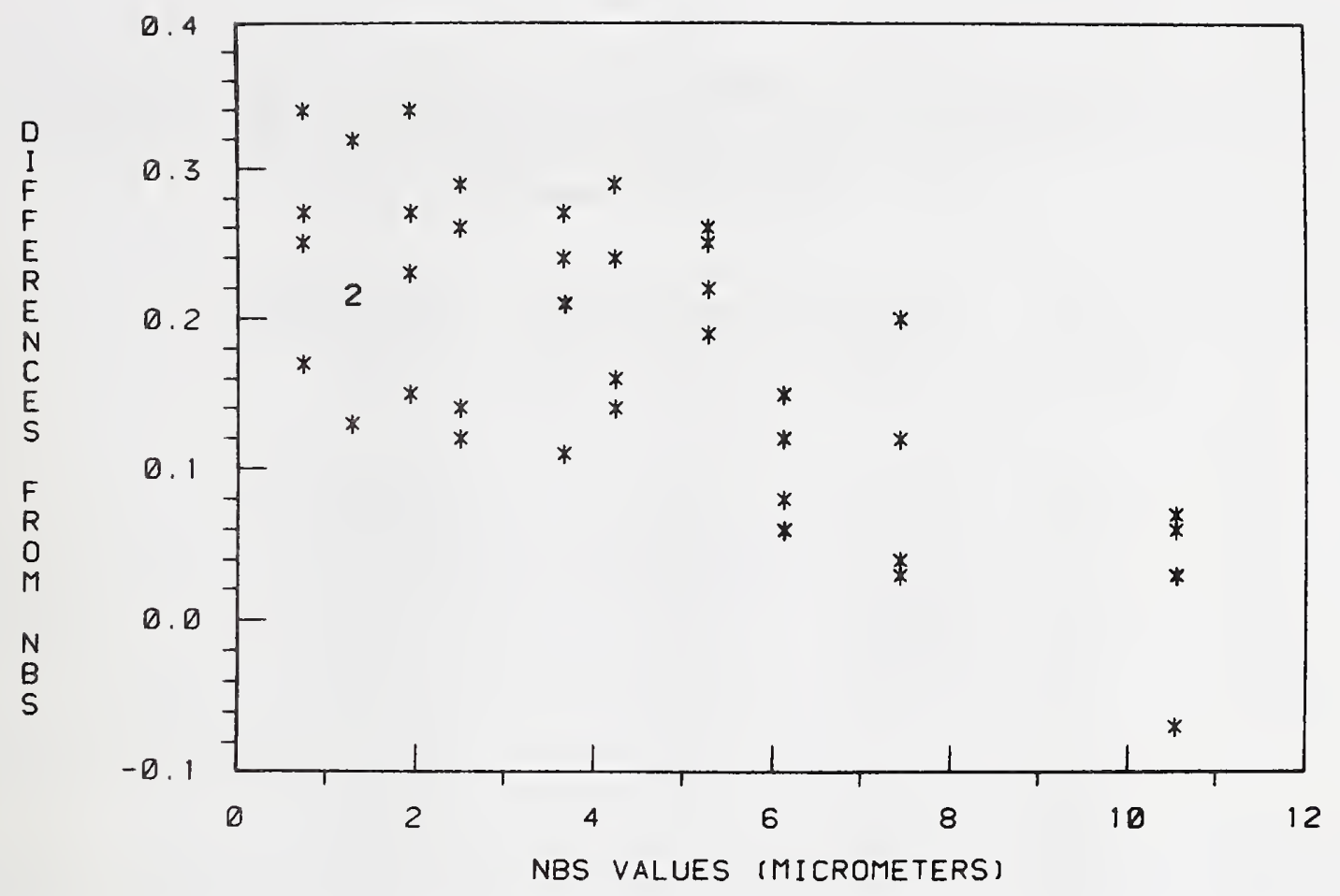

Figure 4: Differences between linewidth measurements and corresponding NBS values plotted against NBS values.

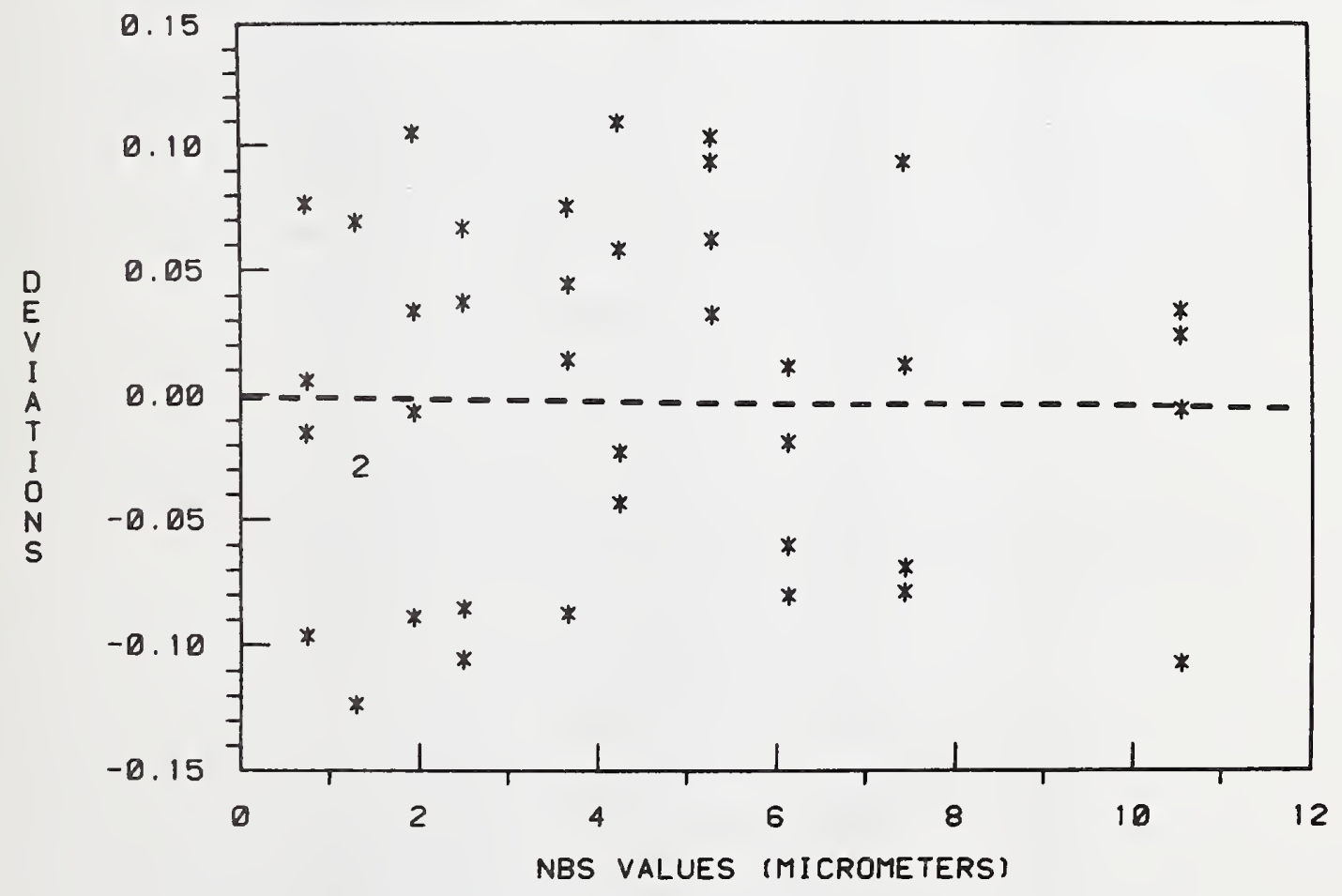

Figure 5: Deviations of observed linewidths from linear calibration curve plotted against NBS values. 
Worksheet B

Calculations for Linewidth Calibration Curve Linewidth Measurements on Opaque Lines Values in Micrometers

\begin{tabular}{|c|c|c|c|}
\hline NBS & Observed & Differences & Deviation \\
\hline Values & Values & from NBS & From Fit \\
\hline w & $z$ & d & $\delta$ \\
\hline 2.50 & 2.62 & 0.12 & -0.1036 \\
\hline 1.94 & 2.17 & 0.23 & -0.0066 \\
\hline .74 & .99 & 0.25 & -0.0145 \\
\hline 4.25 & 4.39 & 0.14 & -0.0429 \\
\hline 10.56 & 10.63 & 0.07 & 0.0339 \\
\hline 5.29 & 5.54 & 0.25 & 0.0913 \\
\hline 3.67 & 3.94 & 0.27 & 0.0736 \\
\hline 7.45 & 7.57 & 0.12 & 0.0116 \\
\hline 1.30 & 1.43 & 0.13 & -0.1215 \\
\hline 6.14 & 6.26 & 0.12 & -0.0189 \\
\hline 2.50 & 2.76 & 0.26 & 0.0364 \\
\hline 1.94 & 2.28 & 0.34 & 0.1034 \\
\hline .74 & 1.01 & 0.27 & 0.0055 \\
\hline 4.25 & 4.54 & 0.29 & 0.1071 \\
\hline 10.56 & 10.49 & -0.07 & -0.1061 \\
\hline 5.29 & 5.48 & 0.19 & 0.0313 \\
\hline 3.67 & 3.88 & 0.21 & 0.0136 \\
\hline 7.45 & 7.48 & 0.03 & -0.0784 \\
\hline 1.30 & 1.52 & 0.22 & -0.0315 \\
\hline 6.14 & 6.20 & 0.06 & -0.0789 \\
\hline 2.50 & 2.64 & 0.14 & -0.0836 \\
\hline 1.94 & 2.09 & 0.15 & -0.0866 \\
\hline .74 & .91 & 0.17 & -0.0945 \\
\hline 4.25 & 4.41 & 0.16 & -0.0229 \\
\hline 10.56 & 10.59 & 0.03 & -0.0061 \\
\hline 5.29 & 5.51 & 0.22 & 0.0613 \\
\hline 3.67 & 3.78 & 0.11 & -0.0864 \\
\hline 7.45 & 7.49 & 0.04 & -0.0684 \\
\hline 1.30 & 1.52 & 0.22 & -0.0315 \\
\hline 6.14 & 6.22 & 0.08 & -0.0589 \\
\hline 2.50 & 2.79 & 0.29 & $0.0 \overline{664}$ \\
\hline 1.94 & 2.21 & 0.27 & 0.0334 \\
\hline .74 & 1.08 & 0.34 & 0.0755 \\
\hline 4.25 & 4.49 & 0.24 & 0.0571 \\
\hline 10.56 & 10.62 & 0.06 & 0.0239 \\
\hline 5.29 & 5.55 & 0.26 & 0.1013 \\
\hline 3.67 & 3.91 & 0.24 & 0.0436 \\
\hline 7.45 & 7.65 & 0.20 & 0.0916 \\
\hline 1.30 & 1.62 & 0.32 & 0.0685 \\
\hline 6.14 & 6.29 & 0.15 & 0.0111 \\
\hline
\end{tabular}


Calculations for finding a linewidth calibration curve such that $\mathrm{z}=\mathrm{a}+\mathrm{bw}$ for $n$ measurements:

$$
\begin{aligned}
& \mathrm{n}=10 \mathrm{k}=40 \\
& \mathrm{~d}=\mathrm{z}-\mathrm{w} \\
& \overline{\mathrm{w}}=\Sigma \Sigma \mathrm{w} / \mathrm{n}=4.384 \\
& \overline{\mathrm{z}}=\Sigma \Sigma \mathrm{z} / \mathrm{n}=4.564
\end{aligned}
$$

Estimate of slope $\hat{b}=\Sigma \Sigma(z-\bar{z})(w-\bar{w}) / \Sigma \Sigma(w-\bar{w})^{2}=0.9767$

Estimate of intercept $\hat{a}=\bar{z}-\hat{b} \bar{w}=0.2817$

Deviations from linear fit $\delta=z-z^{\prime \prime}$ where $z^{\prime \prime}=\hat{a}+\hat{b} w$

Standard deviation of linear fit $s=\sqrt{\sum \sum \delta^{2} /(n-2)}=0.06826$

with degrees of freedom $n-2=38$

Student's t-test for intercept:

Standard deviation of a $s=s \sqrt{\frac{\sum \sum w^{2}}{n \Sigma \Sigma(w-\bar{w})^{2}}}=0.01955$

$t$ statistic for intercept $t_{1}=a / s=14.4$

Critical value $t_{.025}(38)=2.0$

$$
\begin{aligned}
& t_{1}>t_{0} 025 \begin{array}{l}
\text { implies that a is significantly } \\
\text { different than zero. }
\end{array}
\end{aligned}
$$

Student's t-test for slope:

Standard deviation of $\mathrm{b}_{\mathrm{b}}^{\mathrm{s}}=\mathrm{s} / \sqrt{\sum \sum(\mathrm{w}-\overline{\mathrm{w}})^{2}}=0.00372$

$t$ statistic for slope $\quad t_{2}=(1-b) / s=6.3$

Critical value $t_{.025}(38)=2.0$

$$
t_{2}>t_{.025} \begin{aligned}
& \text { implies that } b \text { is significantly } \\
& \text { different than one. }
\end{aligned}
$$


Specifically what can go wrong with the calibration procedure so that values corrected by the calibration curve do not have the desirable property of negligible offset from NBS? Possible sources of error that could affect this accuracy, some of which have already been discussed, are summarized in this section. A thorough analysis of the initial calibration data should be undertaken before the calibration program is put into operation, and if significant sources of errors are identified by this analysis, such problems should be rectified, and the initial calibration experiment should be repeated.

\section{i) Lack of precision.}

The inability to repeat measurements adequately with the system operating over a range of diverse conditions affects the accuracy of the results. Such lack of precision as indicated by a process standard deviation that is large relative to the accuracy goal of the program, is a key statistic alerting one that unidentified sources of error are afflicting the system. There is nothing intrinsic to the statistical treatment that will improve precision. The calibration curve is a device for reducing systematic error, and improvements, in precision will have to come from adherence to the NBS recommended procedures for adjusting the microscope and from changes in operating conditions in the laboratory. It is important to realize that measurement assurance, while making abundant use of statistical methodology, is not achieved by statistics alone, but by the totality of procedures that relate the system to the NBS photometric system.

ii) Outliers in the initial calibration data.

Outliers in the initial calibration data can seriously distort the calibration curve especially if they lie near one of the endpoints of the calibration interval. Formal tests for the types of outliers encountered in the interlaboratory study are not given in this document because they require considerable computing capability, but they can be found in reference [2].

\section{iii) Non-linearity of the calibration curve.}

The assumption of linearity is crucial in justifying the validity of the results for the entire calibration interval. The NBS artifact is designed for systems with linear responses relative to the values assigned to the lines on the artifact. Modelling a process that is non-linear in a given region of the calibration interval would require an artifact with lines closer together over that region. A statistical test for linearity is included in the appendix.

\section{iv) Differences among operators.}

It is possible for different operators to produce measurements that have offsets that are different in sign and in magnitude. If the measurement system includes several operators, one may accept this source of error as part of the imprecision of the process by including several operators in the initial calibration experiment. This would certainly require a total of more than four repetitions. If the measurement system includes very few operators who consistently produce significantly different offsets, it may be worthwhile to establish separate calibration curves for each operator. 
v) Lack of system control.

The calibration procedures outlined in this publication are dependent upon a calibration curve which is assumed to be valid for the system in its future operation. This assumption must be checked continuously because if the system response drifts or occasionally takes unpredictable excursions, the resulting values will not be properly corrected for offset. A procedure for exercising control over the calibration curve is discussed in section 6 .

vi) Differences among repetitions in the initial calibration data.

The calibration curve will not produce satisfactory results if there is an essential difference in the response of the system from repetition to repetition; $i . e .$, if the slope and intercept of the calibration curve do not correctly characterize the individual repetitions. This source of error is checked by plotting the differences between the observed linewidths and the NBS values for the linewidths against the NBS values. Connecting the points for a single repetition enables one to see the type of variation that exists among repetitions. If the slopes and intercepts of linear functions fitted to the data for each individual repetition are changing in sign or are significantly different in magnitude, the calibration curve, which is based on the averages of the repetitions, will not properly correct the system at any given time.

Comparison of slopes and intercepts can be done graphically as in Figure 6 in which the responses for each repetititon are connected by solid lines with the corresponding fitted linear functions shown by dashed lines. This example illustrates that even where the overall cluster of calibration data appears to indicate a linear response, examination of the finer structure of the individual repetitions reveals very disparate responses including changes in the sign of the slope. A formal statistical test is given in appendix II.

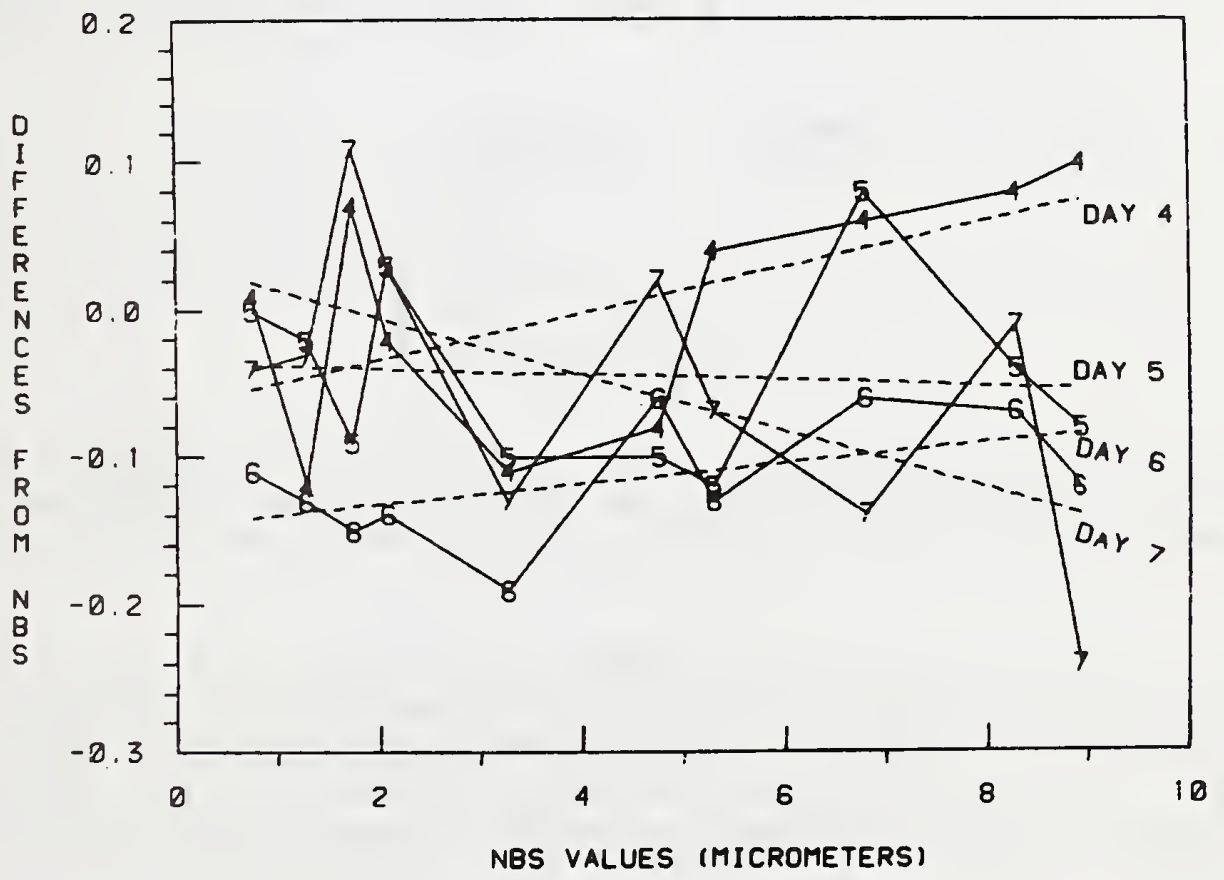

Figure 6: Daily changes in calibration curve. Differences for one day are connected by solid lines, and the corresponding calibration curve is represented by a dashed line. 
5. What is the precision of the optical system and how is it estimated?

The term system precision refers to the ability to repeat measurements on the optical system from day to day or from occasion to occasion. It is based on the fact that repeated measurements on the same physical object such as an opaque line will not be identical, and the variation or scatter inherent in such measurements is referred to as the system precision. It is usually estimated by a standard deviation.

The standard deviation is computed from repeated measurements of the linewidths, and the repetitions must include all conditions for which the precision is assumed to be valid; i.e., they should include all the normal operating conditions in the laboratory. The repetitions should be sufficiently separated in time so as to adequately characterize the system. They should also span the range of linewidths of interest.

The standard deviation from the linear fit for the linewidth calibration curve is the usual estinate of the system precision. It is a proper estimate as long as the mathematical model, in this case we have assumed a linear relationship, is valid.

If there are a sufficient number of repeated measurements at each line over the entire regime of $0.5 \mu \mathrm{m}-12 \mu \mathrm{m}$, then the standard deviation of each line is an estimate of the system precision, and the pooled standard deviation over all lines is also an estimate of this precision. For example, for linewidths $z_{i j}(i=1, \ldots, k ; j=1, \ldots, 10)$ where $i$ denotes the repetition and $j$ denotes the line, the standard deviation for the jth line is

$$
s_{j}=\left(\frac{\sum_{i=1}^{k}\left(z_{i j}-\bar{z}_{j}\right)^{2}}{k-1}\right)^{\frac{1}{2}} \text { where } \bar{z}_{j}=\frac{\sum_{i=1}^{k} z_{i j}}{k}
$$

The pooled standard deviation is

$$
s_{p}=\left(\frac{\sum_{j=1}^{10}(k-1) s_{j}^{2}}{10(k-1)}\right)^{\frac{1}{2}}
$$

Each of the standard deviations $s_{1}, s_{2}, \ldots, s_{10}$ has $(k-1)$ degrees of freedom, and the pooled standard deviation $s_{p}$ has $10(k-1)$ degrees of freedom. These calculations are illustrated for data on opaque lines from the interlaboratory study in Worksheet $\mathrm{C}$.

The question arises, "Should the standard deviation from the linear fit or the pooled standard deviation be quoted as the estimate of process precision?" The preferred one is usually the one with the larger number of degrees of freedom, i.e., the standard deviation from the linear fit, but there are occasions when the pooled standard deviation is the more useful as described in section 7 . 


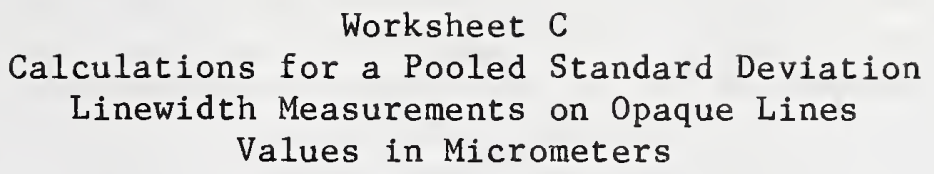

Lines

$\mathrm{z}_{1}$

$\mathbf{z}_{2}$

$z_{3}$

24

$\bar{z}$

2.42

2.56

2.44

2.59

2. 502

2.00

1.978

0.86

0.770

4.31

4.278

4.21

0.78

0.68

10.53

4.36

4.23

10.39

10.49

10.52

10.482

5.37

5.31

5.38

5.38

5.360

3.72

3.688

$7.43 \quad 7.34$

3.59

7.51

7.408

1.21

1.30

1.30

1.40

1.302

6.06

6.13

6.082

$s_{j}$

$6.10 \quad 6.04$

$s_{j}=\sqrt{\sum_{1}^{4}(z-\bar{z})^{2} / 3} \quad, j=1, \ldots, 10$

Calculation of pooled standard deviation

$$
s_{p}=\sqrt{\frac{\sum(k-1) s_{j}^{2}}{10(k-1)}}=0.0692
$$

Degrees of freedom $=10(k-1)=30$ 
6. How long will the derived calibration curve be adequate for correcting dimensional measurements?

Establishment of a calibration curve based on the recommended number of repetitions (a minimum of four sets of measurements on ten lines) constitutes the first step in what can become a full fledged measurement assurance program for linewidth measurements. The measurement assurance concept requires continual surveillance on the output of the calibrated system to ensure that the system is behaving accordingly; otherwise, the applied corrections based on the established calibration curve may degrade instead of improve the accuracy of the resulting value. That is, it must be demonstrated that the system is responding as presumed by utilizing a control procedure that is capable of detecting significant changes.

This can be accomplished by exercising quality control on the calibration curve itself in much the same way that quality control is exercised on individual components in a process. A test built into the operational procedure at given intervals can be used to see if the values corrected by the calibration curve meet the requirement of having negligible offset from NBS. The method for controlling the output of the system as corrected by the calibration curve is in keeping with a control chart approach.

This approach requires making one set of measurements on the ten lines on the artifact at least at the start-up of the measurement sequence or as often as experience dictates and testing for out-of-control conditions after each set of measurements. If ten measurements impose too great a burden on the workload, one should consider measuring only three of the lines--making sure that two of the lines are near the two endpoints of the calibration interval and that one is near the center. In fact, fewer control measurements at frequent intervals may be preferable to all ten measurements at infrequent intervals. One could alternate lines from occasion to occasion. The application of the control test will be easier, however, if the same number of lines are checked each time.

In order to conform to our previous notation, let $z_{1}^{* *}(i=1, \ldots, m)$ denote the corrected linewidth measurements (see equation 3.2 ) and $w_{i}$ denote the assigned values $^{2}$ for the respective lines where $m \leqslant 10$. If the optical system is perfectly calibrated by the calibration curve, the quantities $v_{1}$, referred to as the control values, have expected values of zero where

$$
v_{1}=z_{1}^{* *}-w_{1} \quad i=1, \ldots, m
$$

2 The quantities $w_{i}$ refer to the NBS assigned values if the calibrated pattern on the SRM is used for control purposes. In order to minimize contamination on the SRM, it is preferable to use a secondary standard for control purposes, in which case the quantities $w_{i}$ refer to the values assigned to the secondary standard according to the procedures in section 3 . 
The control values should be evenly distributed about zero and fall within the appropriate upper and lower control limits. It is recommended that all control values be plotted as a function of time as in Figure 7 . This will result in $m$ values at each interval. If one or more values falls outside of the control limits, the system is out-of-control at that time. Such a finding precludes using the calibration curve to correct the system. The control measurements and statistical test for control should be repeated at that point, the workload being discontinued until the system is brought back into control. Continued failures should trigger an investigation into the cause and may indicate a permanent change, in which case the initial calibration measurements should be repeated and the calibration curve reestablished.

The calculation of the upper and lower control limits depends on $s$ the estimate of system precision from the linear fit, $v$ the number of degrees of freedom associated with $s$, and $m$ the number of control values. For probability level $1-\alpha$, the upper and lower limits should be chosen as follows:

$$
\begin{aligned}
& \text { Upper control limit } \ell_{1}=s_{c} t_{\alpha / 2}^{*}(\nu) \\
& \text { Lower control limit } \ell_{2}=-s_{c} t_{\alpha / 2}^{*}(\nu)
\end{aligned}
$$

where the standard deviation of the control is $s_{c}=\frac{s}{a}$

b

and the critical values of the $t^{*}$ distribution with $v$ degrees of freedom are tabulated for $\mathrm{m}=10$ and $\mathrm{m}=3$ for $\alpha=.05$ in Table 2.1 and for $\alpha=0.01$ in Table 2.2.

Statistical control in the context of a calibration curve infers not only that measurements on a given line are repeatable within certain limits but also that the system response remains linear. Because the test is sensitive to departures from linearity, control limits based on $\alpha=0.05$ will produce stringent control on the calibrated values; less stringent control can be achieved with control limits based on $\alpha=0.01$.

One example of calculations for control purposes for $m=3$ and $\alpha=0.05$ is shown in Worksheet D, and the control values are plotted in Figure 7. Note that the lines defining the lower endpoint, mid-point, and upper endpoint of the calibration curve are denoted by $L, M$ and $U$ respectively in the graph. This convention enables one to identify consistently non-linear behavior. 


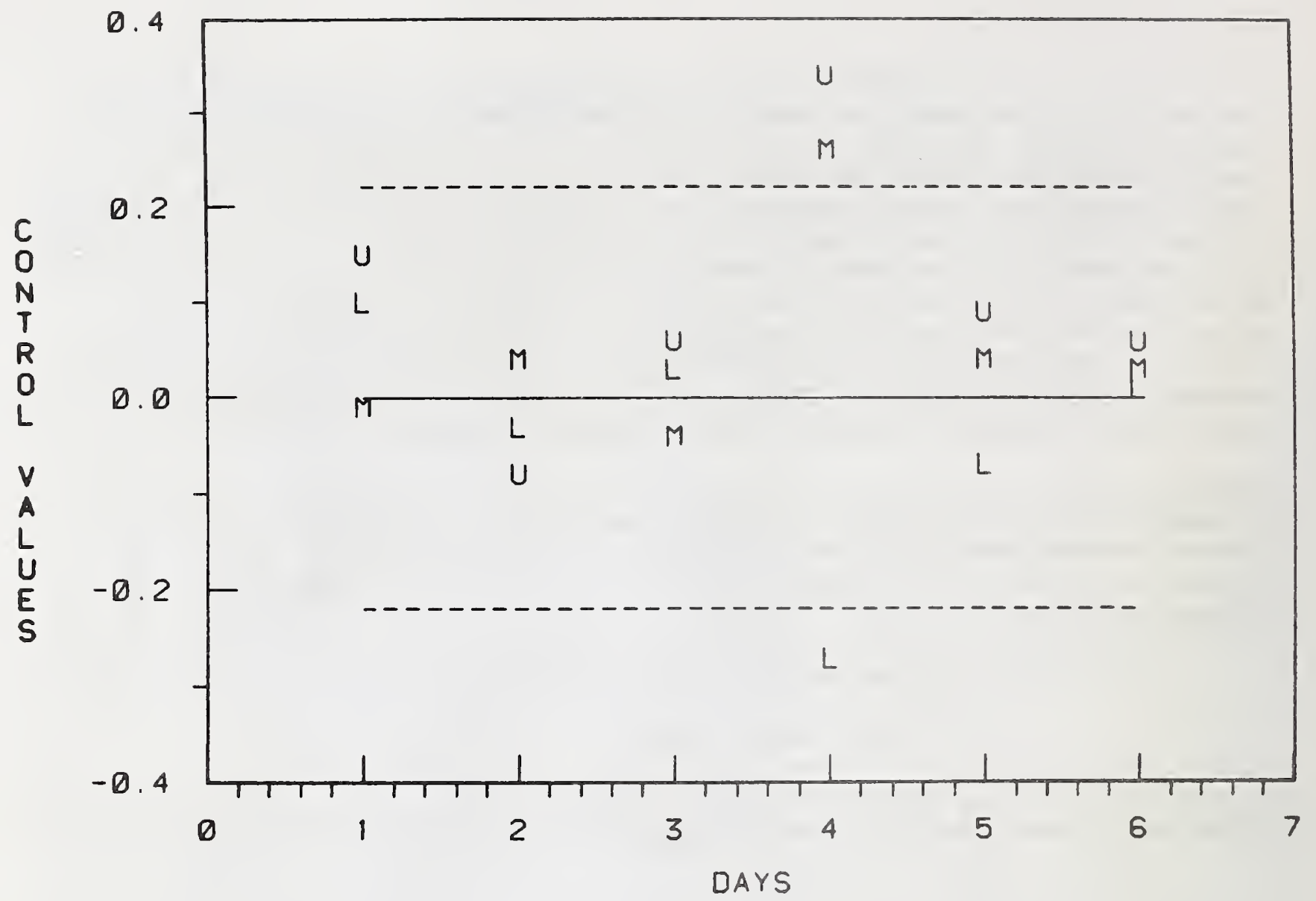

Figure 7: Control chart for opaque 1inewidths for data in Worksheet D. Control limits computed for significance level $\alpha=0.05$.

The graphical method of looking for control values that are outside of the control limits is synonomous with testing each control value in the following way:

$$
\text { If } v_{i}>\ell_{1} \text { or if } v_{i}<\ell_{2} \text { for any } i \quad i=1, \ldots, m
$$

the system is judged out-of-control. This test is easily implemented on a computer or even by hand, but the benefit derived from plotting the control data periodically should not be overlooked. The test is capable of detecting only large changes in the behavior of the system, and the plots provide additional information alerting one to a system that is gradually changing over time and providing information about the precision of the process. 
Worksheet D

Calculations for Control of Measurement Process at the $\alpha=0.05$ Significance Leve1

\section{Linewidth Measurements on Opaque Lines at $\mathrm{m}=3$ Points}

Values in Micrometers

\begin{tabular}{|c|c|c|c|c|c|}
\hline Repetition & $\begin{array}{c}\text { NBS } \\
\text { Value } \\
\text { w }\end{array}$ & $\begin{array}{l}\text { Observed } \\
\text { Value } \\
z\end{array}$ & $\begin{array}{c}\text { Corrected } \\
\text { Value } \\
z_{* *}\end{array}$ & $\begin{array}{c}\text { Control } \\
\text { v }\end{array}$ & $\begin{array}{l}\text { Upper } \\
\text { Limit } \\
\ell_{1}\end{array}$ \\
\hline 1 & $\begin{array}{l}0.76 \\
3.29 \\
8.89\end{array}$ & $\begin{array}{l}1.12 \\
3.49 \\
9.11\end{array}$ & $\begin{array}{l}0.86 \\
3.28 \\
9.04\end{array}$ & $\begin{array}{r}0.10 \\
-0.01 \\
0.15\end{array}$ & $\begin{array}{l}0.17 \\
0.17 \\
0.17\end{array}$ \\
\hline 2 & $\begin{array}{l}0.76 \\
3.29 \\
8.89\end{array}$ & $\begin{array}{l}0.99 \\
3.53 \\
8.89\end{array}$ & $\begin{array}{l}0.73 \\
3.33 \\
8.81\end{array}$ & $\begin{array}{r}-0.03 \\
0.04 \\
-0.08\end{array}$ & $\begin{array}{l}0.17 \\
0.17 \\
0.17\end{array}$ \\
\hline 3 & $\begin{array}{l}0.76 \\
3.29 \\
8.89\end{array}$ & $\begin{array}{l}1.05 \\
3.46 \\
9.02\end{array}$ & $\begin{array}{l}0.79 \\
3.25 \\
8.95\end{array}$ & $\begin{array}{r}0.03 \\
-0.04 \\
0.06\end{array}$ & $\begin{array}{l}0.17 \\
0.17 \\
0.17\end{array}$ \\
\hline 4 & $\begin{array}{l}0.76 \\
3.29 \\
8.89\end{array}$ & $\begin{array}{l}0.76 \\
3.75 \\
9.30\end{array}$ & $\begin{array}{l}0.49 \\
3.55 \\
9.23\end{array}$ & $\begin{array}{r}-0.27 d \\
0.26 \checkmark \\
0.34 d\end{array}$ & $\begin{array}{l}0.17 \\
0.17 \\
0.17\end{array}$ \\
\hline 5 & $\begin{array}{l}0.76 \\
3.29 \\
8.89\end{array}$ & $\begin{array}{l}0.96 \\
3.53 \\
9.05\end{array}$ & $\begin{array}{l}0.69 \\
3.33 \\
8.98\end{array}$ & $\begin{array}{r}-0.07 \\
0.04 \\
0.09\end{array}$ & $\begin{array}{l}0.17 \\
0.17 \\
0.17\end{array}$ \\
\hline 6 & $\begin{array}{l}0.76 \\
3.29 \\
8.89\end{array}$ & $\begin{array}{l}1.03 \\
3.52 \\
9.02\end{array}$ & $\begin{array}{l}0.77 \\
3.32 \\
8.95\end{array}$ & $\begin{array}{l}0.01 \\
0.03 \\
0.06\end{array}$ & $\begin{array}{l}0.17 \\
0.17 \\
0.17\end{array}$ \\
\hline
\end{tabular}

$\checkmark$ Indicates that control value is either $>\ell_{1}$ or $\left\langle\ell_{2}\right.$.

Linewidth calibration from Worksheet $B$

$$
\begin{array}{ll}
\hat{a}=0.2817 & \hat{b}=0.9767 \\
\hat{s}=0.06826 &
\end{array}
$$

Correction$$
z^{* *}=\frac{1}{\hat{b}}(z-\hat{a})
$$

Control Values

$$
\mathrm{v}=\mathrm{z}^{* *}-\mathrm{w}
$$

Upper Control Limit

$l_{1}=\frac{\mathrm{s}}{\hat{\mathrm{b}}} \mathrm{t}^{*} .025(38) \quad \mathrm{t}^{*} .025(38)=2.498$ from Table 2.1

Lower Control Limit

$$
\ell_{2}=-\ell_{1}
$$


Another example is presented to clarify some of the ideas presented in this section. A linear calibration curve was established for an optical.system using the NBS SRM, and the subsequent control measurements taken over eight days are plotted in Figure 8; measurements for each day are connected in order to demonstrate the strengths and weaknesses of a control procedure based on $\mathrm{m}=3$ control points. Control values for the lower, mid, and upper endpoints and associated control limits were calculated for the existing calibration curve and are plotted in Figure 9.

The four data points that are outside of the control limits in Figure 9 are marked accordingly in Figure 8. Notice that the endpoints are the most sensitive to change and that point $\|_{4}$ is unquestionably out-of-control. But what about the other three data points that are outside of the control limits? Is it as apparent that they represent a significant change in the system? One fact is apparent from a perusal of Figure 9 that cannot be gleaned from Figure 8 ; i.e., almost all of the control values are above the zero line indicating that the system has drifted since the initial calibration curve was established.

Furthermore, the curves in Figure 8 raise a basic question about whether or not a linear calibration curve is adequate for this system. Significant findings for points 非 1 and 非 2 reflect a combination of non-1inearity in the lower end of the system and overall drift. The question about the linearity assumption cannot be answered directly by the control procedure, but the out-of-control points flag a deficiency in the system; i.e., that the values corrected by the linear calibration curve will not meet the requirement of having negligible offset from NBS. That is precisely the question in which the user should be interested.

Finally, the system drift and multiple out-of-control conditions that are documented by the control procedure provide sufficient evidence that the derived calibration curve no longer is adequate for correcting linewidth measurements. The calibration curve should be reestablished from more recent measurements on the system, and this new calibration curve should be monitored at frequent intervals until one is satisfied that the system is no longer drifting and is operating consistently in control. 
If all ten lines are being measured as part of the control process, it is advantageous to keep track of the individual measured values, and periodically, at convenient intervals, to add the accumulated control data to the calibration data. If a smaller number of control measurements are made regularly, the entire calibration curve should be repeated occasionally so that the parameters can be updated.

The slope and intercept and assoclated estimate of random error should be revised based on this updated data set. This can be done simply by using the updated data as in Worksheet $B$ to estimate the necessary parameters which in turn become the accepted parameters for the system and are used to correct the linewidth values until the next update. Assuming the system remains in statistical control, this will result in a smaller uncertainty for the corrected values as the calibration curve is tied down by a larger data base.

However, for some computer automated systems with limited storage capacities, it may be more convenient to save the averages of $k$ repetitions made on each line during the calibration sequence rather than the individual measurements and to update this data base after every $K$ succeeding control sequences. In this case the pooled standard deviations from each sequence should be combined to form the estimate of process precision. Note that a calibration curve based on averages will yield the same estimates of the slope and intercept as one based on the raw data as long as each average contains the same number of data points, but the residual standard deviation, in this case, is not an estimate of process precision.

For example, let $\bar{z}_{j}(j=1, \ldots, 10)$ be the averages of $k$ repetitions on each Iine and $s_{p}$ the corresponding pooled standard deviation. Also let

$\bar{Z}_{j}(j=1, \ldots, 10)$ be the averages of $K$ succeeding repetitions on each line with pooled standard deviation $S_{p}$. (See equations (5.1) and (5.2) In the last section for pooled standard deviations.)

Thus the averages

$$
z^{\prime}{ }_{j}=\frac{k \bar{z}_{j}+k \bar{z}_{j}}{k+k} \quad j=1, \ldots, 10
$$

form a data base for updating the calibration curve given the model

$$
z^{\prime}{ }_{j}=a^{\prime}+b^{\prime} w_{j} \quad j=1, \ldots, 10
$$


The estimates of the updated parameters (denoted by ') are:

$$
\hat{b}^{\prime}=\sum_{j} \frac{\left(z_{j}^{-}-\bar{z}^{-}\right)\left(w_{i}-\bar{w}\right)}{\sum_{j}\left(w_{i}-\bar{w}\right)^{2}}
$$

$$
\hat{a^{\prime}}=y^{\prime}-\hat{b^{\prime}} \bar{w}
$$

The residual standard deviation of the fit with 8 degrees of freedom is

$$
s^{\prime}=\left(\sum_{j}\left(z^{\prime} j-\hat{a^{\prime}-\hat{b^{\prime}} w_{j}}\right)^{2}\right)^{\frac{1}{2}}
$$

Although $s^{\prime}$ can be used to estimate the system precision $s$ where

$$
s=s^{\prime} \sqrt{k+K}
$$

the pooled standard deviation

$$
s_{p}^{\prime}=\left(\frac{10(k-1) s_{p}^{2}+10(k-1) s_{p}^{2}}{10(k+k-2)}\right)^{\frac{1}{2}}
$$

with $10(k+K-2)$ degrees of freedom is a better estimate of process precision. These calculations are illustrated in Worksheet E.

Obviously the data base can be updated after each control sequence; i.e., for $\mathrm{K}=1$, but no additional information is available for computing $s^{\prime} p$. In this case, the only way to get an updated estimate of the process precision is via equation $(7.4)$.

There are several possible variations on the schemes outlined above for updating the data base. The mechanics of updating the data base are usually dependent on the degree of automation that exists in the laboratory and should be carefully thought out before implementation. 
Worksheet $\mathrm{E}$

Calculations for Updating the Calibration Curve

Linewidth Measurements on Opaque Lines

Values in Micrometers

\begin{tabular}{ccccc} 
& \multicolumn{4}{c}{ Averages of } \\
\cline { 3 - 4 } Lines & $\begin{array}{c}\text { NBS } \\
\text { Values } \\
\mathrm{W}\end{array}$ & $\begin{array}{c}\text { From Calibration } \\
\text { Runs }\end{array}$ & $\begin{array}{c}\text { From Control } \\
\text { Runs }\end{array}$ & $\begin{array}{c}\text { Updated } \\
\text { Values } \\
z^{-}\end{array}$ \\
1 & 2.50 & 2.502 & 2.498 & 2.499 \\
2 & 1.94 & 1.978 & 1.983 & 1.981 \\
3 & 0.74 & 0.770 & 0.775 & 0.773 \\
4 & 4.25 & 4.278 & 4.277 & 4.277 \\
5 & 10.56 & 10.482 & 10.478 & 10.479 \\
6 & 5.29 & 5.360 & 5.360 & 5.360 \\
7 & 3.67 & 3.688 & 3.688 & 3.688 \\
8 & 7.45 & 7.408 & 7.409 & 7.409 \\
9 & 1.30 & 1.302 & 1.298 & 1.299 \\
10 & 6.14 & 6.082 & 6.077 & 6.079
\end{tabular}


Values $\bar{z}^{-}$are averages of $k=4$ calibrations from Worksheet $C$.

Values $\bar{Z}^{\prime}$ are averages of $K=8$ control runs.

Pooled standard deviation for calibration data is

$$
s_{p}=0.0692 \text { from Worksheet } C
$$

Pooled standard deviation for control data is

$$
\mathrm{S}_{\mathrm{p}}=0.0610
$$

Updated data base:

$$
\begin{gathered}
z^{\prime}=\frac{k \bar{z}+k \bar{z}}{k+k} \\
\bar{z}^{\prime}=\Sigma z^{\prime} / 10=4.3844 \quad \bar{w}=\Sigma w / 10=4.384
\end{gathered}
$$

Updated calibration curve:

$$
\begin{aligned}
& \hat{b^{\prime}}=\Sigma\left(z^{-}-\bar{z}^{\prime}\right)(w-\bar{w}) / \Sigma(w-\bar{w})^{2}=0.9893 \\
& \hat{a^{\prime}}=\bar{z}^{-}-\hat{b}^{-} \bar{w}=0.0473
\end{aligned}
$$

Updated pooled standard deviation

$$
s_{p}^{\prime}=\sqrt{\frac{10(k-1) s_{p}^{2}+10(k-1) s_{p}^{2}}{10(k+k-2)}}=0.0636
$$

with $\gamma=10(k+k-2)=100$ degrees of freedom. 
Because the functional relationship between the user's system and the NBS system is not known exactly but is estimated by a series of repeated measurements, the calibration curve itself has some imprecision associated with it. Also if the measurement on a line is repeated, the resulting value will not be exactly the same; i.e., the optical system has some imprecision associated with it. This combination creates some difficulty in finding the uncertainty appropriate for the calibrated values. The difficulty arises from the fact that the initial set of measurements used to derive the calibration curve is used over and over again, and limits to error must be computed for all future corrected linewidth values based on this calibration curve. 3

Tracking system performance with control data and consistently revising the linewidth calibration curve with the same control data leads to either refinement of the calibration curve or its periodic reestablishment. In either case, the control data is a connecting thread that characterizes the output of the system.

The standard deviation of a calibrated value will be largest for lines near the endpoints of the calibration interval. Therefore, it is suggested that a standard deviation be computed for the endpoints based on the control data and that it be used as a miximum for all intervening lines. Assume that there have been $p$ control sequences each of which produced $m$ acceptable control values, $v_{j l}, \ldots, v_{j m}(j=1, \ldots, p)$. Then the control values for the endpoints, namely $v_{j l}$ and $v_{j m}(j=1, \ldots, p)$ can be used to compute

$$
s_{\mathrm{CAL}}=\left(\frac{\sum v_{j 1}^{2}+\sum_{j} v_{j m}^{2}}{2 p}\right)^{\frac{1}{2}}
$$

with $2 p$ degrees of freedom. For a given line with calibrated value $z * *$, the usual confidence interval statement that (1- $\alpha$ ) percent of all calibrations for that line are contained in the interval $z^{* *} \pm \mathrm{L}$ where

$$
L=s_{C A L} t_{\alpha / 2}(2 p)
$$

is approximately true for the endpoints and conservatively true for all other lines.

When sufficient data does not exist for this analysis, a tolerance type interval, called a Scheffe ${ }^{\prime}$ interval, based on the initial calibration curve can be constructed. This calculation, although cumbersome, should be used at least for the initial uncertainty statement and can be revised after several updates of the calibration curve have been completed.

3 In cases where the calibration curve is being utilized only once, the reader is referred to a paper by C. Eisenhart (1939) "The interpretation of certain regression methods and their use in biological and industrial research," Annals of Math Stat, 10 , pp. 162-202. 
The approach developed by Scheffe' [14] guarantees that a large percentage of statements that are made about future calibrations are correct. The statements refer to limits to error which are appropriate for the corrected values. For example, these limits $L$ can be constructed such that the probability is $>0.99$ that 95 percent of all intervals $z^{* *} \mp \mathrm{L}$ so constructed contain the linewidth value that is properly related to NBS where $z^{* *}$ is a corrected linewidth measurement.

The Scheffe' procedure is conservative and will yield fairly wide intervals depending on the choice of $\alpha$ and $\delta$. The statement that the probability is $1-\delta$ that $(1-\alpha)$ percent of the intervals so constructed are correct should be defined according to the user's requirements. Scheffe suggests that $\delta$ be chosen smaller than $\alpha$, and a combination of $\alpha=0.10$ and $\delta=0.05$ may be appropriate for most situations. More conservative limits are given by a choice of $\alpha=0.05$ and $\delta=0.01$. Tables are provided to accommodate both sets of statements.

The calculation of the limits produces upper and lower curves bounding the calibration curve resulting in upper and Jower limits for each nominal linewidth. The upper and lower limits are not necessarily symmetrical, but were sufficiently close for the data in the interlaboratory study that only the procedure for calculating the upper limits is given here. For example, the following limits are calculated for the linewidth calibration curve derived in Worksheet $C$ for $\alpha=0.05$ and $\delta=0.01$.

$\begin{array}{crc}\text { Values in Micrometers } \\ \text { Nominal Linewidth } & \begin{array}{c}\text { Limits to Error } \\ \text { Upper L }\end{array} & \text { Lower L } \\ & 0.25 & -0.26 \\ 1 & 0.24 & -0.25 \\ 2 & 0.24 & -0.24 \\ 3 & 0.23 & -0.23 \\ 4 & 0.23 & -0.23 \\ 5 & 0.24 & -0.24 \\ 6 & 0.25 & -0.24 \\ 7 & 0.26 & -0.25 \\ 8 & 0.27 & -0.26 \\ 9 & 0.28 & -0.27 \\ 10 & \end{array}$

The maximum of these limits to error occurs at one of the endpoints of the calibration interval and is appropriate for use in the uncertainty statement. The steps necessary for computing the maximum limit to error L based on reference [14] are given on the next page, and it is noted that the calculation should not be extended to linewidths outside of the calibration interval. The steps outlined assume that the calibration curve is linear and that the estimate of precision has $n-2$ degrees of freedom. 
Choose probabilities $\alpha$ and $\delta$.

Look up $\mathrm{Z}_{\alpha / 2}$ the upper $\alpha / 2$ percentage point of the normal distribution. $\mathrm{Z}_{\alpha / 2}=1.96$ for $\alpha=0.05$ $\mathrm{z}_{\alpha / 2}=1.6449$ for $\alpha=0.10$ $\chi_{1-\delta}^{2}(\nu)$ The lower $\delta$-percentage point of the chi- freedom. Table 3.1 gives values of $x_{1-\delta}^{2}(\nu)$ for
$\delta=.01$ and $\nu=30(2) 120$. and Table 3.2 gives values for $\delta=0.05$.

$F_{\delta}(2, v)$ is the upper $\delta$-percentage point of the $F$ distribution with 2 degrees of freedom in the numerator and $v$ degrees of freedom in denominator $(\nu=n-2)$. Table 4.1 gives values of $F_{\delta}(2, \nu)$ for $\delta=.01$ and $\nu=30(2) 120$, and Table 4.2 gives values for $\delta=0.05$.

Compute

$$
c_{1}=c_{3} z_{\alpha / 2} \sqrt{\nu}\left(x_{1-\delta}^{2}(\nu)\right)^{-1 / 2} \quad c_{2}=c_{3} \sqrt{2 F_{\delta}(p, \nu)}
$$

The value of $\mathrm{C}_{3}$ depends on several parameters and ranges between 0.95 and 1.05 for $\delta=.01$ and $n=40$. The exact value of $C_{3}$ which is appropriate for any data set can be found using methods given in reference [5]. The calculation of $L$ is not overly sensitive to $\mathrm{C}_{3}$. For the interlaboratory study $\mathrm{C}_{3}$ was taken to be 1.05 , and this value is suggested as a conservative estimate of $\mathrm{C}_{3}$ and is used in the sample calculation in Worksheet G.

Find the least-squares estimates $\mathrm{a}, \mathrm{b}$ and $\mathrm{s}$ for the calibration curve

$$
z_{i j}=a+b w_{i j} \quad i=1, \ldots, k ; j=1, \ldots, 10
$$

and choose $w_{\max }$ to be the maximum linewidth of interest.

Compute

$$
\begin{gathered}
\mathrm{C}=\hat{\mathrm{b}}^{2}-\left(\mathrm{C}_{2} \mathrm{~s}_{\mathrm{b}}\right)^{2} \\
\mathrm{D}=\mathrm{w}_{\max }-\hat{\mathrm{a}}-\hat{\mathrm{b}} \overline{\mathrm{w}}+\mathrm{C}_{1} \mathrm{~s}
\end{gathered}
$$

where $\bar{w}$ is the average of the NBS values. The limit $L$ is given by

$$
L=\bar{w}-w^{\prime}+\frac{\hat{b D}+C_{2}\left(\frac{s^{2} C}{n}+D^{2} s^{2}\right)^{\frac{1}{2}}}{C} \text { where } w^{\prime}=\frac{w_{\max }-\hat{a}}{\hat{b}}
$$

The computations for the linewidth calibration curve derived in worksheet $\mathrm{C}$ for $\alpha=.05$ and $\delta=.01$ are shown in Worksheet $\mathrm{F}$.

Finally, the uncertainty that is appropriate for a corrected linewidth value is $\mp U$ where $U=L+\left|\Delta_{N B S}\right|$ and $\Delta_{N B S}$ is the systematic error from the NBS system. 
Worksheet $\mathrm{F}$

Calculation of Limits to Error L for Opaque Linewidth Values

Corrected by a Linear Calibration Curve

Values in Micrometers

Intercept a

Slope b

Standard deviation of intercept $s_{a}$

Standard deviation of slope $\mathbf{s}_{\mathrm{b}}$

Standard deviation of linear fit $s$

Degrees of freedom

Mean of NBS values $\bar{W}$
0.2817

0.9767

0.01955

0.003717

0.06826

38

4.384

Choose $\alpha=.05, \delta=.01$

Look up in tables:

$Z_{.025}=1.96$ the upper $2.5 \%$ point of the normal distribution

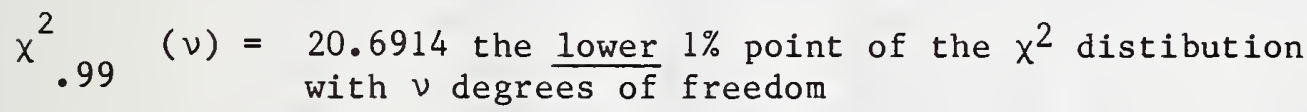

F.01 $(2, v)=5.2112$ the upper $1 \%$ point of the $F$ distrubution with 2 and $v$ degrees of freedom

Compute:

$$
\mathrm{C}_{1}=1.05 \mathrm{Z}{ }_{.025} \sqrt{\nu} / \sqrt{\chi^{2} .99(\nu)}=2.795 \quad \mathrm{C}_{2}=1.05 \sqrt{2 \mathrm{~F} .01(2, \nu)}=3.3898
$$

Choose $\mathrm{w}_{\max }=10$ and compute

$$
\begin{aligned}
\mathrm{C} & =\hat{\mathrm{b}^{2}}-\left(\mathrm{C}_{2} \mathrm{~s}_{\mathrm{b}}\right)^{2}=0.9794 \\
\mathrm{D} & =\mathrm{w}_{\max }-\hat{\mathrm{a}}-\hat{\mathrm{b}} \overline{\mathrm{w}}+\mathrm{C}_{1} \mathrm{~s}=5.8144 \\
\mathrm{w}^{\prime} & =\frac{\mathrm{w}_{\frac{\max }{\hat{b}}-\hat{a}}=10.1520}{\mathrm{~b}} \\
\overline{\mathrm{w}} & =\sum \mathrm{w}_{\mathrm{i}} / \mathrm{n}=4.384 \\
\mathrm{~L} & =\overline{\mathrm{w}}-\mathrm{w}^{\prime}+\frac{\hat{b} \mathrm{D}+\mathrm{C}_{2} \sqrt{\frac{\mathrm{Cs}^{2}}{\mathrm{n}}+\mathrm{D}^{2} \mathrm{~s}^{2}}}{\mathrm{C}}=0.28
\end{aligned}
$$

The maximum limit to error that is appropriate for any corrected opaque linewidth in the $1-10 \mu \mathrm{m}$ interval is $\mathrm{L}=0.28 \mu \mathrm{m}$. 
Table 1

Critical Values of Student's $t$ Distribution

for a Two-Sided Test

Significance Level $\alpha=0.05$

$\begin{array}{lrrr}\nu & t .025(\nu) & v & t .025(v) \\ 30 & 2.042 & 76 & 1.992 \\ 32 & 2.037 & 78 & 1.991 \\ 34 & 2.032 & 80 & 1.990 \\ 36 & 2.028 & 82 & 1.989 \\ 38 & 2.024 & 84 & 1.989 \\ 40 & 2.021 & 86 & 1.988 \\ 42 & 2.018 & 88 & 1.987 \\ 44 & 2.015 & 90 & 1.987 \\ 46 & 2.013 & 92 & 1.986 \\ 48 & 2.011 & 94 & 1.985 \\ 50 & 2.009 & 96 & 1.985 \\ 52 & 2.007 & 98 & 1.985 \\ 54 & 2.005 & 100 & 1.984 \\ 56 & 2.003 & 102 & 1.984 \\ 58 & 2.002 & 104 & 1.983 \\ 60 & 2.000 & 106 & 1.983 \\ 62 & 1.999 & 108 & 1.982 \\ 64 & 1.998 & 110 & 1.982 \\ 66 & 1.997 & 112 & 1.981 \\ 68 & 1.995 & 114 & 1.981 \\ 70 & 1.994 & 116 & 1.981 \\ 72 & 1.993 & 118 & 1.980 \\ 74 & 1.993 & 120 & 1.980\end{array}$

$\checkmark$ is the number of degrees of freedom in the estimate of process precision. 
Table 2.1

Critical Values of $t^{*}$ distribution

for controlling the output of a calibration curve at $\mathrm{m}$ points

Significance level $\alpha=0.05$

\begin{tabular}{|c|c|c|c|c|c|}
\hline \multicolumn{4}{|c|}{${ }^{*} .025(v)$} & \multicolumn{2}{|c|}{$t^{*} .025(\nu)$} \\
\hline$v$ & $\mathrm{~m}=3$ & $\mathrm{~m}=10$ & $\gamma$ & $m=3$ & $\mathrm{~m}=10$ \\
\hline 30 & 2.528 & 3.021 & 76 & 2.442 & 2.883 \\
\hline 32 & 2.519 & 3.006 & 78 & 2.440 & 2.881 \\
\hline 34 & 2.511 & 2.993 & 80 & 2.439 & 2.879 \\
\hline 36 & 2.504 & 2.982 & 82 & 2.437 & 2.877 \\
\hline 38 & 2.498 & 2.972 & 84 & 2.436 & 2.875 \\
\hline 40 & 2.492 & 2.963 & 86 & 2.435 & 2.873 \\
\hline 42 & 2.487 & 2.954 & 88 & 2.434 & 2.872 \\
\hline 44 & 2.482 & 2.947 & 90 & 2.433 & 2.870 \\
\hline 46 & 2.478 & 2.940 & 92 & 2.432 & 2.868 \\
\hline 48 & 2.474 & 2.934 & 94 & 2.431 & 2.867 \\
\hline 50 & 2.470 & 2.929 & 96 & 2.430 & 2.866 \\
\hline 52 & 2.467 & 2.923 & 98 & 2.429 & 2.864 \\
\hline 54 & 2.464 & 2.919 & 100 & 2.428 & 2.863 \\
\hline 56 & 2.461 & 2.914 & 102 & 2.428 & 2.861 \\
\hline 58 & 2.459 & 2.910 & 104 & 2.427 & 2.860 \\
\hline 60 & 2.456 & 2.906 & 106 & 2.426 & 2.859 \\
\hline 62 & 2.454 & 2.903 & 108 & 2.425 & 2.858 \\
\hline 64 & 2.452 & 2.900 & 110 & 2.425 & 2.857 \\
\hline 66 & 2.450 & 2.896 & 112 & 2.424 & 2.856 \\
\hline 68 & 2.448 & 2.893 & 114 & 2.423 & 2.855 \\
\hline 70 & 2.446 & 2.891 & 116 & 2.423 & 2.854 \\
\hline 72 & 2.444 & 2.888 & 118 & 2.422 & 2.853 \\
\hline 74 & 2.443 & 2.886 & 120 & 2.421 & 2.852 \\
\hline
\end{tabular}

Critical values $t_{\alpha / 2}^{*}(\nu)$ correspond to the upper $\zeta$ percent point of student's $t$ distribution where

$$
\zeta=1 / 2\left\{1-\exp \left(\frac{\ln (1-\alpha)}{\mathrm{m}}\right)\right\}
$$

and $\nu$ is the number of degrees of freedom in the estimate of process precision. 
Table 2.2

Critical values of $t^{*}$ distribution

for controlling the output of a calibration curve

at $m$ points

Significance level $\alpha=0.01$

\begin{tabular}{|c|c|c|c|c|c|}
\hline \multicolumn{4}{|c|}{$t^{*} .005(\nu)$} & \multicolumn{2}{|c|}{$t^{*} .005(v)$} \\
\hline$v$ & $\mathrm{~m}=3$ & $\mathrm{~m}=10$ & $v$ & $\mathrm{~m}=3$ & $\mathrm{~m}=10$ \\
\hline 30 & 3.187 & 3.644 & 76 & 3.030 & 3.422 \\
\hline 32 & 3.171 & 3.620 & 78 & 3.027 & 3.418 \\
\hline 34 & 3.156 & 3.599 & 80 & 3.025 & 3.415 \\
\hline 36 & 3.143 & 3.581 & 82 & 3.023 & 3.412 \\
\hline 38 & 3.131 & 3.564 & 84 & 3.020 & 3.409 \\
\hline 40 & 3.121 & 3.549 & 86 & 3.018 & 3.406 \\
\hline 42 & 3.111 & 3.536 & 88 & 3.016 & 3.403 \\
\hline 44 & 3.103 & 3.524 & 90 & 3.014 & 3.400 \\
\hline 46 & 3.095 & 3.513 & 92 & 3.013 & 3.398 \\
\hline 48 & 3.088 & 3.504 & 94 & 3.011 & 3.396 \\
\hline 50 & 3.082 & 3.495 & 96 & 3.009 & 3.393 \\
\hline 52 & 3.076 & 3.486 & 98 & 3.008 & 3.391 \\
\hline 54 & 3.070 & 3.479 & 100 & 3.006 & 3.389 \\
\hline 56 & 3.065 & 3.471 & 102 & 3.005 & 3.387 \\
\hline 58 & 3.060 & 3.465 & 104 & 3.003 & 3.385 \\
\hline 60 & 3.056 & 3.459 & 106 & 3.002 & 3.383 \\
\hline 62 & 3.052 & 3.453 & 108 & 3.001 & 3.382 \\
\hline 64 & 3.048 & 3.448 & 110 & 3.000 & 3.380 \\
\hline 66 & 3.045 & 3.443 & 112 & 2.998 & 3.378 \\
\hline 68 & 3.041 & 3.438 & 114 & 2.997 & 3.377 \\
\hline 70 & 3.038 & 3.434 & 116 & 2.996 & 3.375 \\
\hline 72 & 3.035 & 3.429 & 118 & 2.995 & 3.373 \\
\hline 74 & 3.032 & 3.426 & 120 & 2.994 & 3.372 \\
\hline
\end{tabular}

Critical values $t_{\alpha / 2}^{*}(\nu)$ correspond to the upper $\zeta$ percent point of student's $t$ distribution where

$$
\zeta=1 / 2\left\{1-\exp \left(\frac{\ln (1-\alpha)}{\mathrm{m}}\right)\right\}
$$

and $\nu$ is the number of degrees of freedom in the estimate of process precision. 
Table 3.1

$$
\begin{aligned}
& \text { Percentage points of the } \chi^{2} \text { distribution } \\
& \text { Lower } 1 \% \text { points }
\end{aligned}
$$

$\begin{array}{llll}v & x^{2}{ }^{2}(v) & \nu & x^{2}(v) \\ & & & \\ 30 & 14.953 & 76 & 50.286 \\ 32 & 16.362 & 78 & 51.910 \\ 34 & 17.789 & 80 & 53.540 \\ 36 & 19.233 & 82 & 55.174 \\ 38 & 20.691 & 84 & 56.813 \\ 40 & 22.164 & 86 & 58.456 \\ 42 & 23.650 & 88 & 0.103 \\ 44 & 25.148 & 90 & 61.754 \\ 46 & 26.657 & 92 & 63.409 \\ 48 & 28.177 & 94 & 65.068 \\ 50 & 29.707 & 96 & 66.730 \\ 52 & 31.246 & 98 & 68.396 \\ 54 & 32.793 & 100 & 70.065 \\ 56 & 34.350 & 102 & 71.737 \\ 58 & 35.913 & 104 & 73.413 \\ 60 & 37.485 & 106 & 75.092 \\ 62 & 39.063 & 108 & 76.774 \\ 64 & 40.649 & 110 & 78.458 \\ 66 & 42.240 & 112 & 80.146 \\ 68 & 43.838 & 114 & 81.836 \\ 70 & 45.442 & 116 & 83.529 \\ 72 & 47.051 & 118 & 85.225 \\ 74 & 48.666 & 120 & 86.923\end{array}$

$\nu$ is the number of degrees of freedom in the estimate of process precision. 
Table 3.2

Percentage points of the $\chi^{2}$ distribution Lower $5 \%$ points

$\begin{array}{llll}v & x^{2}(v) & v & x^{2}(v) \\ & & & \\ 30 & 18.95 & & \\ 32 & 20.0793 & 76 & 56.920 \\ 34 & 21.664 & 78 & 58.654 \\ 36 & 23.269 & 80 & 60.391 \\ 38 & 24.884 & 82 & 62.132 \\ 40 & 26.509 & 84 & 63.876 \\ 42 & 28.144 & 86 & 65.623 \\ 44 & 29.787 & 90 & 67.373 \\ 46 & 31.439 & 92 & 70.882 \\ 48 & 33.098 & 94 & 72.640 \\ 50 & 34.764 & 96 & 74.401 \\ 52 & 36.437 & 98 & 76.164 \\ 54 & 38.116 & 100 & 77.929 \\ 56 & 39.801 & 102 & 79.697 \\ 58 & 41.492 & 104 & 81.468 \\ 60 & 43.188 & 106 & 83.240 \\ 62 & 44.889 & 108 & 85.015 \\ 64 & 46.595 & 110 & 86.792 \\ 66 & 48.305 & 112 & 88.570 \\ 68 & 50.020 & 114 & 90.351 \\ 70 & 51.739 & 116 & 92.134 \\ 72 & 53.462 & 118 & 93.918 \\ 74 & 55.189 & 120 & 95.705\end{array}$

$\nu$ is the number of degrees of freedom in the estimate of process precision. 


$$
\begin{aligned}
& \text { Table } 4.1 \\
& \text { Percentage points of the F distribution } \\
& \text { Upper } 1 \% \text { points }
\end{aligned}
$$

$\begin{array}{ccrc}\nu & F .01(2, \nu) & \nu & F .01(2, \nu) \\ 30 & 5.390 & 76 & 4.896 \\ 32 & 5.336 & 78 & 4.888 \\ 34 & 5.289 & 80 & 4.881 \\ 36 & 5.248 & 82 & 4.874 \\ 38 & 5.211 & 84 & 4.867 \\ 40 & 5.178 & 86 & 4.861 \\ 42 & 5.149 & 88 & 4.855 \\ 44 & 5.123 & 90 & 4.849 \\ 46 & 5.099 & 92 & 4.844 \\ 48 & 5.077 & 94 & 4.838 \\ 50 & 5.057 & 96 & 4.833 \\ 52 & 5.038 & 98 & 4.828 \\ 54 & 5.021 & 100 & 4.824 \\ 56 & 5.006 & 102 & 4.820 \\ 58 & 4.991 & 104 & 4.815 \\ 60 & 4.977 & 106 & 4.811 \\ 62 & 4.965 & 108 & 4.807 \\ 64 & 4.953 & 110 & 4.803 \\ 66 & 4.942 & 112 & 4.800 \\ 68 & 4.932 & 114 & 4.796 \\ 70 & 4.922 & 116 & 4.793 \\ 72 & 4.913 & 118 & 4.790 \\ 74 & 4.904 & 120 & 4.786\end{array}$

$\nu$ is the number of degrees of freedom in the estimate of process precision. 
Table 4.2

Percentage points of the $F$ distribution
Upper $5 \%$ points

$\begin{array}{llrl}\nu & F .05(2, \nu) & \nu & F .05(2, \nu) \\ & & & \\ 30 & 3.316 & 76 & 3.117 \\ 32 & 3.294 & 78 & 3.114 \\ 34 & 3.276 & 80 & 3.111 \\ 36 & 3.259 & 82 & 3.108 \\ 38 & 3.245 & 84 & 3.105 \\ 40 & 3.232 & 86 & 3.103 \\ 42 & 3.220 & 88 & 3.100 \\ 44 & 3.209 & 90 & 3.098 \\ 46 & 3.200 & 92 & 3.095 \\ 48 & 3.191 & 94 & 3.093 \\ 50 & 3.183 & 96 & 3.091 \\ 52 & 3.175 & 98 & 3.089 \\ 54 & 3.168 & 100 & 3.087 \\ 56 & 3.162 & 102 & 3.086 \\ 58 & 3.156 & 104 & 3.084 \\ 60 & 3.150 & 106 & 3.082 \\ 62 & 3.145 & 108 & 3.080 \\ 64 & 3.140 & 110 & 3.079 \\ 66 & 3.136 & 112 & 3.077 \\ 68 & 3.132 & 114 & 3.076 \\ 70 & 3.128 & 116 & 3.074 \\ 72 & 3.124 & 118 & 3.073 \\ 74 & 3.120 & 120 & 3.072\end{array}$

$\nu$ is the number of degrees of freedom in the estimate of process precision. 
[1] Jerke, J. M., ed. (February 1980). Semiconductor Measurement Technology: Accurate Linewidth Measurements on Integrated-Circuit Photomasks, NBS Spec. Publ. 400-43.

[2] Jerke, J. M., Croarkin, M. C., and Varner, R. N., Semiconductor Measurement Technology: Interlaboratory Study on Linewidth Measurements for Antireflective Chromium Photomasks, to be published as an NBS Spec. Publ.

[3] Swyt, Dennis A. (January 1978). Design of a Pattern on a Photomask-Like Physical Standard for Evaluation and Calibration of Linewidth-Measuring Systems, Solid State Tech. 21, 35-42.

[4] Reference [1] pp. 7-14.

[5] Nyyssonen, D. (August 1977). Linewidth Measurement with an Optica1 Microscope: The Effect of Operating Conditions on the Image Profile, Appl. Opt. 16, No. ㅇ, 2223-2230.

[6] Nyyssonen, D. (1979), Application of Optical Coherence: The Key to Accurate Optical Micrometrology, Application of Optical Coherence, Vol. 194 (Society of Photo-optical Instrumentation Engineers, Bedingham, Washington).

[7] Cameron, J. M. (April 1977). Measurement Assurance. NBSIR 77-1240.

[8] Reference [1] p. 43.

[9] Reference [1] p. 78.

[10] Procedures for Using SRM-474. Submitted to ASTM Committee F-1 as proposed ASTM Standard.

[11] Reference [2] sec. 3.3.

[12] Neter, John and Wasserman, Wm. (1974). Applied Linear Statistical Models, Richard D. Irwin, Inc., Homewood, IL, 57-62.

[13] Reference [2] sec. 3.8 .

[14] Scheffe , H., Rosenblatt, J. R. and Spiegelman, C. A Statistical Theory of Calibration to be published.

[15] Draper, N. R. and Smith, H. (1966). Applied Regression Analysis, John Wiley \& Sons, Inc., New York, NY, 26-32. 


\section{APPENDIX}

\section{Test of Linearity Assumption.}

The test of whether or not a linear function of the measurements constitutes an appropriate calibration curve is based on the information in the repetitions [15]. The fitted value for each line

$$
\hat{z}_{j}=\hat{a}+\hat{b}_{j}
$$$$
j=1, \ldots, 10
$$

is compared to the average of the repetitions for each line; namely,

$$
\bar{z}_{j}=\frac{\sum_{i=1}^{k} z_{i j}}{k}
$$$$
j=1, \ldots, 10
$$

where $k$ is the number of repetitions of each linewidth.

Close agreement between the fitted curve and these averages is evidence that the hypothesis is correct. The test is based on an F statistic, and the assumption of linearity is rejected if

$$
F=\frac{10(k-1)}{8} \cdot \frac{S S L-S S R}{S S R}>F_{0} 01(8,10(k-1))
$$

where

$$
\begin{aligned}
& \text { SSL }=\sum_{j=1}^{10} \sum_{i=1}^{k}\left(z_{i j}-\hat{z}_{j}\right)^{2} \\
& \operatorname{SSR}=\sum_{j=1}^{10} \sum_{i=1}^{k}\left(z_{i j}-\bar{z}_{j}\right)^{2}
\end{aligned}
$$

and $F_{.01}(8,10(k-1))$ is the upper one percent point of the $F$ distribution with eight degrees of freedom in the numerator and $10(k-1)$ degrees of freedom in the denominator. 
II. Test for Differences Among Repetitions.

The test of whether or not a system with linear response is changing from repetition to repetition is based on the following model; namely,

$$
z_{1 j}=\alpha_{1}+\beta_{1} x_{1 j} \quad \begin{aligned}
& i=1, \ldots, k \\
& j=1, \ldots, 10
\end{aligned}
$$

where

$$
x_{1 j}=w_{i j}-\bar{w}_{1}
$$

and

$$
\bar{w}_{1}=\frac{\sum w_{i j}}{10}
$$

Estimates of the intercepts $\alpha_{1}$ and the slopes $\beta_{i}$ and corresponding standard deviations are computed for each repetition.

$$
\begin{aligned}
& \hat{B}_{1}=\frac{\sum\left(x_{1 j}-\bar{x}_{i}\right)\left(z_{1 j}-\bar{z}_{1}\right)}{\sum\left(x_{1 j}-\bar{x}_{i}\right)^{2}}, 1=1, \ldots, k \\
& \hat{\alpha_{1}}=\bar{z}_{1}-\hat{\beta}_{1} \bar{x}_{1} \\
& \bar{x}_{1}=\frac{\sum x_{1 j}}{10} \quad \bar{z}_{1}=\frac{\sum z_{1 j}}{10} \\
& s_{\alpha_{1}}=\left(\frac{\sum_{j}^{2} x_{1 j}^{2}}{10 \sum_{j}\left(x_{i j}-\bar{x}_{1}\right)^{2}}\right)^{\frac{1}{2}} \\
& s_{B_{i}}=\frac{s}{\left(\sum_{j}\left(x_{1 j}-\bar{x}_{1}\right)^{2}\right)^{\frac{1}{2}}} \\
& s_{1}=\left(\frac{\sum\left(z_{1 j}-\hat{\alpha_{1}}-\hat{\beta_{1}} x_{1 j}\right)^{2}}{8}\right)^{\frac{1}{2}}
\end{aligned}
$$


The test statistic is

$$
\begin{gathered}
F=\frac{1}{2(k-1)}\left\{\begin{array}{l}
\sum\left(\hat{\alpha}_{i}-\bar{\alpha}\right)^{2} \\
\frac{i}{\frac{1}{k} \sum_{i} s^{2}}+\frac{\sum}{\alpha_{i}}\left(\hat{\beta}_{i}-\bar{\beta}\right)^{2} \\
\frac{1}{k} \sum_{i} s_{i}^{2}
\end{array}\right\} \\
\bar{\alpha}=\frac{1}{k} \hat{\alpha}_{i} \quad \bar{\beta}=\frac{1}{k} \sum_{i} \hat{\beta}_{i}
\end{gathered}
$$

where

It is concluded that the system is not consistent from repetition to repetition if

$$
F>F_{.01}(2(k-1), 8 k)
$$

where $F .01(2(k-1), 8 k)$ is the upper one percent point of the $F$ distribution with $2(k-1)$ degrees of freedom in the numerator and $8 k$ degrees of freedom in the denominator. 
NBS-114A (REV. 2-8C)

U.S. DEPT, OF COMM.

BIBLIOGRAPHIC DATA

SHEET (See instructions)

1. PUBLICATION OR

REPORT NO.

NBS TN 1164

2. Performing Organ. Report No. 3. Publication Date

4. TITLE AND SUBTITLE

Measurement Assurance for Dimensional Measurements on Integrated-Circuit Photomasks

5. AUTHOR(S)

Carrol1 Croarkin, Ruth Varner

6. PERFORMING ORGANIZATION (If joint or other than NBS, see instructions)

7. Contract/Grant No.

NATIONAL BUREAU OF STANDARDS

DEPARTMENT OF COMMERCE

WASHINGTON, D.C. 20234

8. Type of Report \& Period Covered

WASHINGTON, D.C. 20234

Final

9. SPONSORING ORGANIZATION NAME AND COMPLETE ADDRESS (Street, City, Stote, ZIP)

Same as item 6 .

10. SUPPLEMENTARY NOTES

[.] Document describes a computer program; SF-185, FIPS Softeware Summary, is attached.

11. ABSTRACT (A 200-word or less factual summary of most significant information. If document includes a significant bibliography or literature survey, mention it here)

Optical Microscope Linewidth-Measurement Standards, SRM-474 and SRM-475, have been developed by NBS for optical imaging systems capable of making line-spacing and linewidth measurements in the $0.5 \mu \mathrm{m}-12 \mu \mathrm{m}$ regime on IC photomasks. Each artifact affords a means of reducing systematic errors via a calibration curve and keeping the optical system in statistical control. Procedures are given for accomplishing these goals along with a discussion of the uncertainty of the calibrated values.

12. KEY WORDS (Six to twelve entries; alphabetical order; capitalize only proper names; and separate key words by semicolons) IC photomask; linear calibration curve; line-spacing; 1inewidth; measurement assurance; photomask; SRM; statistical control of measurement process; tests for systematic error; uncertainty.

13. AVAILABILITY

XUnlimited

$\square$ For Official Distribution. Do Not Release to NTIS

[X Order From Superintendent of Documents, U.S. Government Printing Office, Washington, D.C. 20402.

[.] Order From National Technical Information Service (NTIS), Springfield, VA. 2216I

14. NO. OF PRINTED PAGES

50

15. Price 






$$
-
$$




\section{NBS TECHNICAL PUBLICATIONS}

\section{PERIODICALS}

JOURNAL OF RESEARCH-The Journal of Research of the National Bureau of Standards reports NBS research and development in those disciplines of the physical and engineering sciences in which the Bureau is active. These include physics, chemistry, engineering, mathematics, and computer sciences. Papers cover a broad range of subjects, with major emphasis on measurement methodology and the basic technology underlying standardization. Also included from time to time are survey articles on topics closely related to the Bureau's technical and scientific programs. As a special service to subscribers each issue contains complete citations to all recent Bureau publications in both NBS and nonNBS media. Issued six times a year. Annual subscription: domestic $\$ 18$; foreign $\$ 22.50$. Single copy, $\$ 4.25$ domestic; $\$ 5.35$ foreign.

\section{NONPERIODICALS}

Monographs--Major contributions to the technical literature on various subjects related to the Bureau's scientific and technical activities.

Handbooks-Recommended codes of engineering and industrial practice (including safety codes) developed in cosperation with interested industries, professional organizations, and regulatory bodies.

Special Publications-lnclude proceedings of conferences sponsored by NBS, NBS annual reports, and other special publications appropriate to this grouping such as wall charts, pocket cards, and bibliographies.

Applied Mathematics Series-Mathematical tables, manuals, and studies of special interest to physicists, engineers, chemists, biologists, mathematicians, computer programmers, and others engaged in scientific and technical work.

National Standard Reference Data Series-Provides quantitative data on the physical and chemical properties of materials, compiled from the world's literature and critically evaluated. Developed under a worldwide program coordinated by NBS under the authority of the National Standard Data Act (Public Law 90-396).

NOTE: The principal publication outlet for the foregoing data is the Journal of Physical and Chemical Reference Data (JPCRD) published quarterly for NBS by the American Chemical Society (ACS) and the American Institute of Physics (AIP). Subscriptions, reprints, and supplements available from ACS, 1155 Sixteenth St., NW, Washington, DC 20056.
Building Science Series-Disseminates technical information developed at the Bureau on building materials, components, systems, and whole structures. The series presents research results, test methods, and performance criteria related to the structural and environmental functions and the durability and safety characteristics of building elements and systems.

Technical Notes-Studies or reports which are complete in themselves but restrictive in their treatment of a subject. Analogous to monographs but not so comprehensive in scope or definitive in treatment of the subject area. Often serve as a vehicle for final reports of work performed at NBS under the sponsorship of other government agencies.

Voluntary Product Standards-Developed under procedures published by the Department of Commerce in Part 10, Title 15, of the Code of Federal Regulations. The standards establish nationally recognized requirements for products, and provide all concerned interests with a basis for common understanding of the characteristics of the products. NBS administers this program as a supplement to the activities of the private sector standardizing organizations.

Consumer Information Series-Practical information, based on NBS research and experience, covering areas of interest to the consumer. Easily understandable language and illustrations provide useful background knowledge for shopping in today's technological marketplace.

Order the above NBS publications from: Superintendent of Documents, Government Printing Office, Washington, DC 20402.

Order the following NBS publications-FIPS and NBSIR's-from the National Technical Information Services, Springfield. VA 22161.

Federal Information Processing Standards Publications (FIPS PUB)-Publications in this series collectively constitute the Federal Information Processing Standards Register. The Register serves as the official source of information in the Federal Government regarding standards issued by NBS pursuant to the Federal Property and Administrative Services Act of 1949 as amended, Public Law 89-306 (79 Stat. 1127), and as implemented by Executive Order 11717 (38 FR 12315, dated May 11, 1973) and Part 6 of Title 15 CFR (Code of Federal Regulations).

NBS Interagency Reports (NBSIR)-A special series of interim or final reports on work performed by NBS for outside sponsors (both government and non-government). In general, initial distribution is handled by the sponsor; pub'ic distribution is by the National Technical Information Services, Springfield, VA 22161 , in paper copy or microfiche form. 
U.S. DEPARTMENT OF COMMERCE

National Bureau of Standards

Washington, DC 20234

\section{POSTAGE AND FEES PAID} U.S. DEPARTMENT OF COMMERCE
COM-215

DFFICIAL BUSINESS

Penalty for Private Use, $\$ 300$

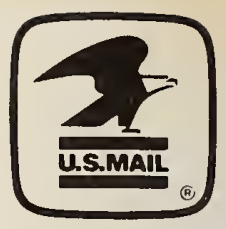

THIAD CLASS

BULK RATE 